\title{
Shallow water benthic imaging and substrate characterization using recreational-grade sidescan-sonar.
}

\author{
Daniel Buscombe* \\ U.S. Geological Survey, Southwest Biological Science Center, Grand Canyon Monitoring and Research \\ Center, Flagstaff, AZ, USA
}

\begin{abstract}
In recent years, lightweight, inexpensive, vessel-mounted 'recreational grade' sonar systems have rapidly grown in popularity among aquatic scientists, for swath imaging of benthic substrates. To promote an ongoing 'democratization' of acoustical imaging of shallow water environments, methods to carry out geometric and radiometric correction and georectification of sonar echograms are presented, based on simplified models for sonar-target geometry and acoustic backscattering and attenuation in shallow water. Procedures are described for automated removal of the acoustic shadows, identification of bed-water interface for situations when the water is too turbid or turbulent for reliable depth echosounding, and for automated bed substrate classification based on singlebeam full-waveform analysis. These methods are encoded in an open-source and freely-available software package, which should further facilitate use of recreational-grade sidescan sonar, in a fully automated and objective manner. The sequential correction, mapping, and analysis steps are demonstrated using a data set from a shallow freshwater environment.
\end{abstract}

Keywords: acoustical remote sensing, benthic habitat, sidescan sonar, habitat mapping

\footnotetext{
${ }^{*}$ Corresponding author

Email address: dbuscombeQusgs.gov (Daniel Buscombe)
} 


\section{Software Availability}

Name of software: PyHum

Version: 1.0

Developer: D. Buscombe

Contact email: dbuscombe@usgs.gov

Year first available: 2015

Available from: Python package index

(https://pypi.python.org/pypi/PyHum);

development versions available on GitHub

(https://github.com/dbuscombe-usgs/PyHum).

\section{Introduction}

\subsection{Acoustic imaging of benthic abiota (bottom substrates and morphologies)}

Sidescan sonar systems have been widely used to map and image benthic environments for over 60 years (e.g. Chesterman et al., 1958; Klein and Edgerton, 1968; Singh et al., 2000; Brown et al., 2011), including the water column and bed, harnessing the radiative properties of sound waves in water (Blondel, 2009). Recent decades have seen increasing use of swath sonar in shallow water, down to less than a meter depth, in fluvial (e.g. Anima et al., 2007; Amiri-Simkooei et al., 2009; Buscombe et al., 2014a,b), lacustrine, and estuarine (e.g. Hobbs, 1985; Kennish et al., 2004) environments, providing high (up to centimetric) resolution acoustic imagery of an area up to thousands of square kilometers per day, principally for 
the purposes of characterizing bottom structure and morphologies; physical and biological substrates; identification of geological facies; for imaging physical structures such as cables, pipelines, and sunken vessels; and detection and characterization of substrates in habitat suitability studies (e.g. Allen et al., 2005; Ehrhold et al., 2006; Yeung and McConnaughey, 2008; Todd and Kostylev, 2011).

Typically, a sidescan sonar system consists of: (1) a topside unit for sonar display and recording; (2) a data transmission cable; and (3) a subsurface streamlined transducer containing a linear array of interconnected transceivers to transmit and receive the acoustic energy. The transducer emits a sound pulse ('beam') in two downward directions (i.e. port and starboard) which is symmetric about, and having broad width in, the vertical plane. The beam is perpendicular to the transducer's direction of forward motion and ensonifies a fan-shaped volume of water. The directionality and intensity of the beam (the directivity pattern) is a function of the operating frequency (in shallow water, typically hundreds of $\mathrm{kHz}$ ) as well as the shape and dimension of the transceiver arrays. The beams are designed to be narrow along-track (parallel to the transducer, or in the direction of the boat) for high-resolution imaging, and fairly wide in the across-track direction (perpendicular to the transducer) in order to maximize bed areal coverage. The swath is the thin strip (footprint) ensonified instantaneously by the sonar (both transducers collectively). A 'ping' consists of the emission of a sound pulse in the water and the simultaneous reception of energy scattered back from the water, then the bed, at increasing range. A short (in time) pulse of emitted sound produces a short (in space) length of sound wave train, resulting in high resolution, but relatively noisy, backscatter data. A longer pulse is typically less sensitive 
to the background noise, at the expense of spatial resolution.

\subsection{The democratization of sidescan sonar technology}

In the past few years, low-cost, consumer-grade (hereafter, 'recreational-grade', to distinguish from 'survey' or 'scientific' grade) sidescan sonar platforms, have been developed for leisure activities such as fishing and hobbyist archeology. Recreational-grade sonar lack standardization in (and description of) the acoustic signal processing used, often without high-quality ('survey grade') positioning and measured boat attitude (heave, pitch, yaw, etc), and reporting of those quantities. It is not usually possible to process data from such sonars using conventional commercial hydrographic surveying software, to post-process the positioning of the scans or carry out a calibration that corrects for radiative properties of individual transducers. However, these inexpensive, lightweight (portable) sidescan sonar units can be deployed on almost any waterborne craft without the requirement of specialist knowledge of sonar and geodetics, and with little to no experience with acoustic remote sensing. This accessibility is behind the rapid increase in popularity of these sonar systems, among the scientific research community for benthic imaging in a range of aquatic environments, both marine and freshwater, lotic and lentic (Kaeser and Litts, 2008; Gonzalez-Socoloske et al., 2009; Collins et al., 2010; Kaeser and Litts, 2010; Havens et al., 2011; Goclowski et al., 2013; Kitchingman et al., 2013; Kaeser et al., 2013; Flowers and Hightower, 2013; Powers et al., 2014; Bilkovic et al., 2014; La Croix and Dashtgard, 2015; Sterrett et al., 2015; Froehlich and Kline, 2015; Buscombe et al., 2015; Cheek et al., 2016; Dunlop et al., 2016; Smit and Kaeser, 2016). Such spatially distributed benthic data are 
especially important in the development and evaluation of models for habitat suitability and vulnerability (e.g. Roberts et al., 2010; Marsili-Libelli et al., 2013; Surridge et al., 2014) since they provide a means to produce georeferenced maps of substrates and bottom morphologies.

This rapid and ongoing 'democratization' of inexpensive sidescan sonar technology will be further facilitated by a technical description of the underlying scope and principles-ofoperation behind these sonar systems and, with their limitations in positioning, attitude, and acoustic standardization in mind, through the development of processing routines, encoded in open-source software, to support a burgeoning interdisciplinary community of users in fields such as hydrology; aquatic ecology; fluvial and coastal geomorphology; and environmental sciences. The present contribution is motivated by this urgent need. Some novel approaches to the processing and georectification of sidescan sonar data are described, implemented in an open-source and freely available software tool, called PyHum, for extracting and working with data from the sidescan sonar in the Humminbird ${ }^{\circledR}$ series (made by Johnson Outdoors Marine Electronics, Inc., Alabama, USA) of pole-mounted fishfinder sonar systems, which to date have emerged as the most popular recreational grade sidescan among scientists. These processing procedures could easily be adapted to work with data recorded by similar recreational sidescan sonar systems, such as those (at the time of writing) made by Lowrance Electronics (Tulsa, Oklahoma, USA) and Garmin Ltd (Schaffhausen, Switzerland), or indeed for any continuous-wave, single-frequency, non-bathymetric, non-interferometric, imaging sonar. Drawing upon the technical literature on sidescan image processing (e.g. Reed and Hussong, 1989; Cervenka and De Moustier, 1993; Collier and Brown, 2005; Burguera and Oliver, 2016) the present contribution details the algorithms, assumptions, and 
structure of a freely available, open-source software designed for ease of use by the nonacoustician.

At the time of writing, at least two proprietary (low-cost yet closed-source) software programs are available for automating rudimentary analyses and for projecting low-cost sidescan data on the bed, namely SonarTRX (http://www.sonartrx.com/web) and Reefmaster (http://reefmaster.com.au). Another semi-automated program, described by Kaeser and Litts (2010), has been developed for use within a Geographic Information System platform to make georectified montages of screenshots from the sonar topside unit, without geometric or radiometric correction. The program PyHum has been produced as an open-source alternative for the use of sidescan sonar data specifically in scientific research, which demands transparency in documentation of the algorithms used, the ability of an individual researcher to adapt the freely available code to her/his specific needs, fostering community development of the software. A physics-based model for the ensonification of the sonar, which is detailed in section 5, is used to correct the sonar data for uneven ensonification, as well as attenuation and other transmission losses caused by the water column. In doing this, PyHum has a potentially much greater scope than existing software for defensible scientific research. Unlike existing software, PyHum accounts for the effect of system gains on depth and slant-range estimates, and provides modules for the removal of echogram shadows, for carrying out spatially distributed textural analyses for substrate classification, and full-waveform echosounder analysis for substrate characterization (which are detailed in the present contribution). In addition, PyHum provides the user with the ability to correct for radiative losses due to water (given user-defined water temperature, salinity and $\mathrm{pH}$ ) and 
suspended sediment (given user-defined sediment concentration and grain size), as well as manually pick the bed and edit noisy scans. PyHum users can modify existing code and add additional modules, as their needs dictate.

\section{Data structure, definitions, and data processing assumptions}

\subsection{Data structure}

The Humminbird ${ }^{\circledR}$ series of 'high definition' sidescan sonars, which use narrowband bursts of continuous sound wave pulses at a single frequency, do not record backscatter phase, so no bathymetric information (from phase) is available. Units record receive-levels in unsigned eight-bit digital integers rather than units of relative acoustic power (such as decibels or decibel-Watts). The units simultaneously record up to four echograms: separate channels for port and starboard sidescan intensity; and up to two channels for singlebeam (downward-looking) echosounder intensity. Positions are reported by the instrument as coordinates in a World Mercator Meters coordinate system (EPSG code 3395, with no UTM zone) but the user of the PyHum toolbox can work with the data in any geographic or projected coordinate system described by Evenden (1990). Other variables recorded per ping are time (in milliseconds elapsed, as well as an epoch/UNIX timestamp), heading (in degrees relative to true North), speed $\left(\mathrm{ms}^{-1}\right)$, and nadir depth $(\mathrm{m})$ which is not corrected for time-varying gain (see section 4). Some acoustically important system variables are described in Table 1.

The port and starboard facing transducers are triggered to simultaneously generate an ultrasonic pulse of sound which interacts with the bed and is partially scattered back to the 


\begin{tabular}{|c|c|}
\hline Variable & Value and units \\
\hline \multicolumn{2}{|l|}{ Sidescan sonar } \\
\hline Transmit power & $10 \log _{10}(1000 \mathrm{~W})=30 \mathrm{~dB} \mathrm{~W}$ \\
\hline Array Length, $t$ & $0.108 \mathrm{~m}$ \\
\hline Pulse duration, $\tau$ & $\approx 85 \mu \mathrm{s}$ \\
\hline Operating frequency, $f$ & 455 or $800 \mathrm{kHz}$ \\
\hline Beam width@ $455 \mathrm{kHz}$ & $86^{\circ}$ \\
\hline Horizontal angular beam width at $3 \mathrm{~dB} @ 455 \mathrm{kHz}\left(\alpha_{3 d B-H}=\sin ^{-1}(c / t f)\right)$ & $1.69^{\circ}$ \\
\hline Horizontal angular beam width at $3 \mathrm{~dB} @ 800 \mathrm{kHz}\left(\alpha_{3 d B-H}=\sin ^{-1}(c / t f)\right)$ & $0.9^{\circ}$ \\
\hline Minimum vertical beam width @ $455 \mathrm{kHz}, \alpha_{V \min }$ & $5^{\circ}$ \\
\hline Maximum vertical beam width @ $455 \mathrm{kHz}, \alpha_{V \max }$ & $64^{\circ}$ \\
\hline Minimum vertical beam width @ $800 \mathrm{kHz}, \alpha_{V \min }$ & $7^{\circ}$ \\
\hline Maximum vertical beam width @ $800 \mathrm{kHz}, \alpha_{V \max }$ & $46^{\circ}$ \\
\hline Vertical angular beam width at $3 \mathrm{~dB} @ 455 \mathrm{kHz}\left(\alpha_{3 d B-V}=\alpha_{V \max }-\alpha_{V \min }\right)$ & $59^{\circ}$ \\
\hline Vertical angular beam width at $3 \mathrm{~dB} @ 800 \mathrm{kHz}\left(\alpha_{3 d B-V}=\alpha_{V \max }-\alpha_{V \min }\right)$ & $39^{\circ}$ \\
\hline \multicolumn{2}{|l|}{ Downward echosounder } \\
\hline Operating frequency & 200 and/or $83 \mathrm{kHz}$ \\
\hline Echosounder beam width@ $200 \mathrm{kHz}$ & $20^{\circ}$ \\
\hline Echosounder beam width @ $83 \mathrm{kHz}$ & $60^{\circ}$ \\
\hline Angular beam width at $3 \mathrm{~dB} @ 200 \mathrm{kHz}(\Psi)$ & $14^{o}$ \\
\hline Angular beam width at $3 \mathrm{~dB} @ 83 \mathrm{kHz}(\Psi)$ & $42^{\circ}$ \\
\hline Equivalent beam angle at $3 \mathrm{~dB} @ 200 \mathrm{kHz}(\psi)$ & 0.0342 steradians \\
\hline Equivalent beam angle at $3 \mathrm{~dB} @ 83 \mathrm{kHz}(\psi)$ & 0.296 steradians \\
\hline
\end{tabular}


transducer as 'backscatter'. The time-series of received echo intensities, or swath, is recorded to disk after pre-processing, pre-amplification and analog-to-digital conversion (Blondel, 2009). Several swaths are gathered as the sonar moves. By aggregating swaths, a 2D acoustic image called an echogram (also called a sonograph), composed of vertical scanlines stacked horizontally (see, for example, Figure 1 in Buscombe et al. (2015)), is constructed. For each ping, the amplitude of the backscattered signal from the water column and bed is recorded as a function of time. Each scanline in a sidescan echogram is composed of pixels which record the intensity at the receiver at an instant in time (a typical intertransmit cycle for a sidescan is a few tens of milliseconds, which includes the ping and the time during which return echoes are detected). The echogram is a mapping of the acoustic response of the bed onto a monochrome 2D digital image (lower intensities are darker), $S[m, n]$ where $m=1 \ldots M$ and $n=1 \ldots N$ are image matrix coordinates, of the backscattering strength (structure and reflectivity) of the bed substrates, $b(x, y)$, where $x$ and $y$ are part of a rectangular coordinate system. Square brackets are used to indicate that $S$ is a discrete variable. Therefore,

$$
\begin{array}{r}
S[m, n]=\left.b(x, y)\right|_{x=x_{s}[m, n]}, \\
y=y_{s}[m, n]
\end{array}
$$

where $x_{s}[m, n]$ and $y_{s}[m, n]$ are the $2 \mathrm{D}$ coordinates of the point on the bed sampled to produce the pixel located at $[m, n], m$ is the spanwise (horizontal) coordinate in the image and $n$ is the longitudinal coordinate representing the track of the vessel, where $\delta n$ (the time between emitted pulses) determines the maximum sensor range in the plane of ensonification, 
and $\delta m$ is controlled by the slant range resolution which is a function of the duration of the emitted sound pulse (pulse length) and the sonar geometry with respect to the bed. The echogram is a distorted representation of the actual river, lake, or sea bed, because it does not take into account the transducer motions (pitch, roll, yaw, heave, etc) between swaths.

Each scanline in an echogram recorded by a downward (nadir)-looking echosounder is composed of pixels which represent a time-series of intensity at the receiver. For the purposes of positioning that time-series, it is assumed to occur at an instant in time and therefore at a single location, $n$. Under this simplification, the echogram is a monochrome 2D digital image, $D[n, i]$ where $n=1 \ldots N$ represents the $1 \mathrm{D}$ track of the vessel (as above) and $i=1 \ldots I$ is a time-series at each $n$th location. The matrix is therefore the time-series of backscattering strength of the bed substrates $b(x, y)$, where $x$ and $y$ are part of a rectangular coordinate system but represent just 1 point in space. Therefore,

$$
\begin{array}{r}
D[n, i]=\left.b(x, y, t)\right|_{x=x_{d}[n]}, \\
y=y_{d}[n], \\
t=t_{d}[i]
\end{array}
$$

where $x_{d}[n]$ and $y_{d}[n]$ are the coordinates of the single point on the bed sampled to produce the pixel located at $n$, and $t_{d}[i]$ are the pixels representing the time-series of echo levels sampled at $[n]$. 


\subsection{Data processing assumptions}

In this contribution, a number of assumptions are made that facilitate the computational tractability of analyzing such data described in section 2.1. First, the sound source is assumed to be continuous wave, the simplest and most common type of sonar signal used in echosounders, consisting of a sine wave at a nominal carrier frequency. The bottom is assumed to be locally planar (i.e. ping-to-ping and pixel-to-pixel) and horizontal. This is a standard assumption in processing sidescan data because co-located bathymetric information is usually not available, and because when the terrain roughness is small compared to the sonar altitude (height above the bed), the errors are small, as shown by Burguera and Oliver (2016).

Further, it is assumed that sound propagates through the water at a constant speed. Geometric distortions caused by variation in the speed of sound with depth, caused by gradients in temperature, pressure, or salinity, are therefore not corrected for, because this information (i.e. sound velocity profile as a function of depth) is rarely known in typical usecases of recreational sidescan, and is usually of minor importance in shallow environments, especially in freshwater (e.g. Buscombe et al., 2014a).

It is further assumed the transducer is pole-mounted and not within a tow-fish, therefore there are no lateral or vertical displacements caused by translational and rotational instabilities of the transducer. The GPS receiver and transducer are assumed to be attached to the same pole and therefore have the same horizontal coordinate. A user-defined vertical offset can be applied between transducer and GPS receiver. Given that the boat attitude (instantaneous values of heave, pitch, roll, yaw, surge, sway, dynamic draft, etc) is unknown 
in most usage cases, it is assumed that there are no lateral or vertical displacements caused by translational and rotational instabilities of the vessel.

Given the lack of compass in most recreational-grade sonar, course-over-ground, which is the actual direction of the vessel rather than a true bearing, is assumed to be equivalent to heading. This could cause significant errors if the boat crabs at an angle while attempting to maintain course in a current. Therefore, it is necessary to operate a recreational grade sidescan sonar flowing with, or directly opposed to, the current, rather than crabbing or ferrying at an angle, as have all the examples in the present contribution.

Given the rapid ping-rate (note that the inter-transmit cycle of a Humminbird ${ }^{\circledR}$ transducer is around $50 \mathrm{~ms}$ ) and the shallow water, it is assumed that there is no positional drift in the transducer between transmission and reception of the acoustic pulse. In other words, the transducer is assumed to be stationary from the start of the ping (the instant the start of the sound pulse is fired) to the end of the ping (the return from the maximum range is received), which allows approximation of scan lines as straight lines and therefore a simple sonar geometric model. Finally, it is assumed that the transducer heading is at a tangent to its instantaneous trajectory. Frequency shifts are not recorded, so it is not possible to quality-control backscattered amplitudes based on the relative speed of the vessel and the target. However, during signal conditioning the analog signal is band-pass filtered so only frequencies close to the transmit frequency are considered, which effectively removes any Döppler shift effects (Betts et al., 2010). 


\section{Field data}

The routines and procedures detailed in the sections below are illustrated using a single example data set collected using a Humminbird ${ }^{\circledR}$ SI 998 unit, from the Colorado River in Grand Canyon, Arizona, just above the confluence of the Little Colorado River at river mile 61 (approximately $98 \mathrm{~km}$ downstream of Lee's Ferry, Arizona). It is a mixed sand-gravelrock alluvial channel with a range of flow depths and speeds. The riverbed at this site has been described, qualitatively and using other sonar and underwater imagery, in Anima et al. (2007), Buscombe et al. (2014b) and Buscombe et al. (2015). Figure 1 shows the boat track during the survey, color-coded by heading, speed and water depth. The survey took just a few minutes to complete from a aluminum-hulled boat motoring downstream in the current. The raw echogram consists of a $2000 \times 90 \mathrm{~m}$ acoustic image of the riverbed (Figure 2).

\section{Echosounding and sidescan slant-range correction}

\subsection{Time-varying-gain range-correction}

The slant-range to the bed location represented by the $m$ th pixel in $S[m, n]$ is $r[m]=$ $c T[m] / 2$, where $T[m]$ is the two-way travel time to that location, and $c$ is the speed of sound in water $\left(\mathrm{ms}^{-1}\right)$. This must be corrected for time-varying gain (TVG), which is an amplifier gain applied to the receive echo level, designed to correct for transmission losses in order to minimize the range-effects on recorded echo levels (Blondel, 2009), but also has a small effect on the reported range itself because the TVG does not start until after a delay period, which is the sum of the transmit pulse duration, $\tau$, and a delay factor, $t_{0}$. The effect of this 


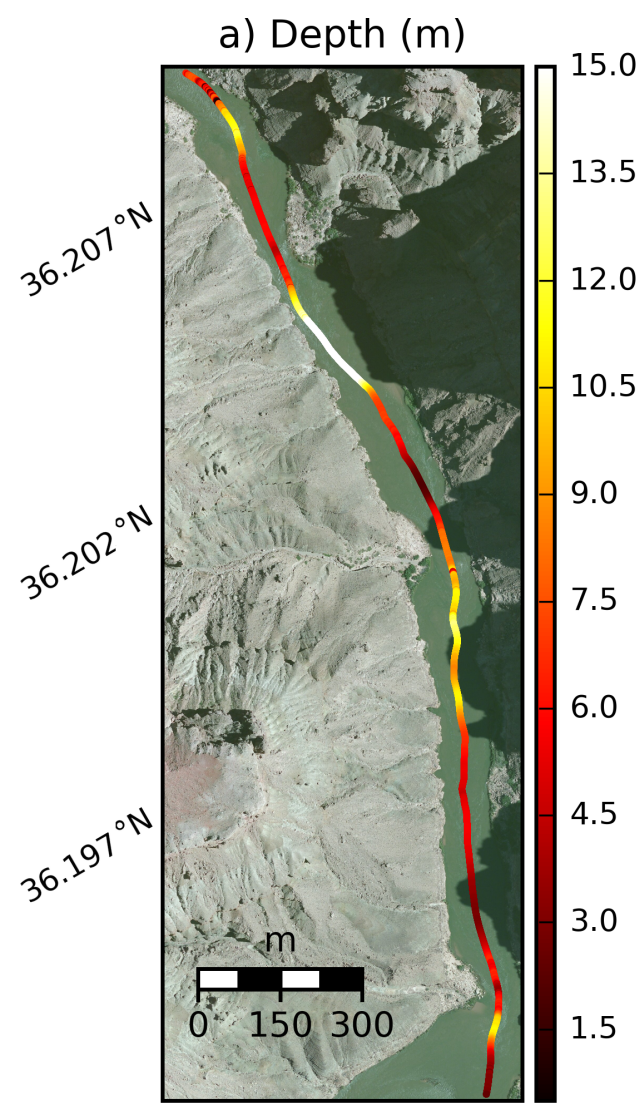

b) Heading (deg N)

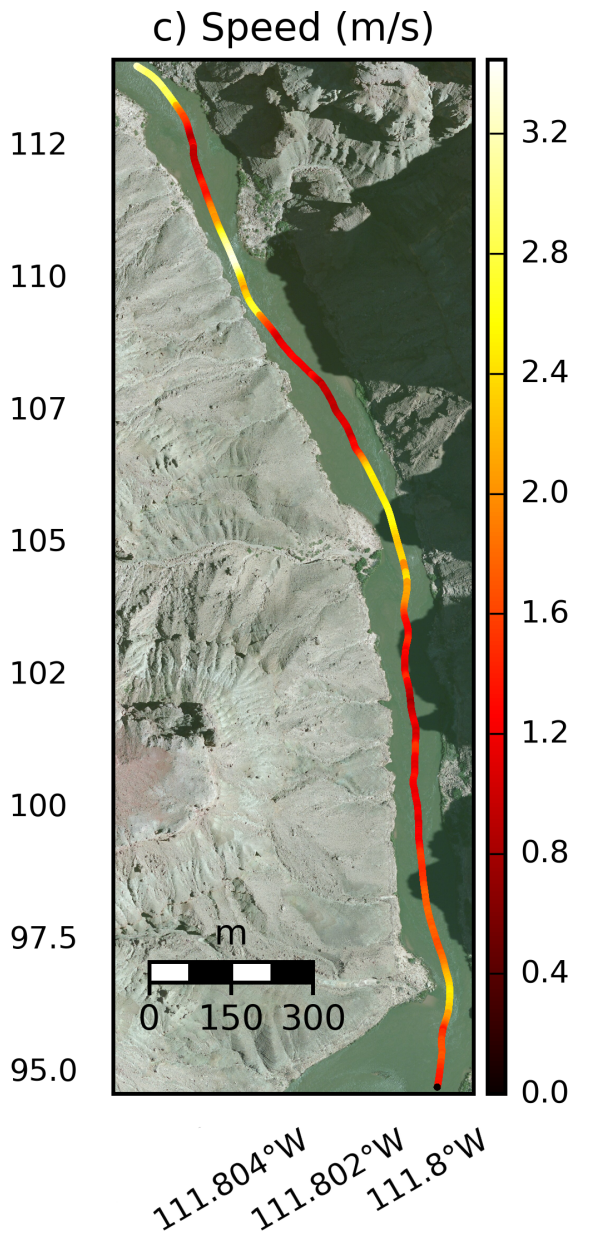

Figure 1: Track made by the boat-mounted transducer in the April 2015 sidescan survey, colorcoded by, from left to right, a) depth in meters, b) course-over-ground heading in degrees from true north, and c) instantaneous speed in meters per second. The river flows from top to bottom. 


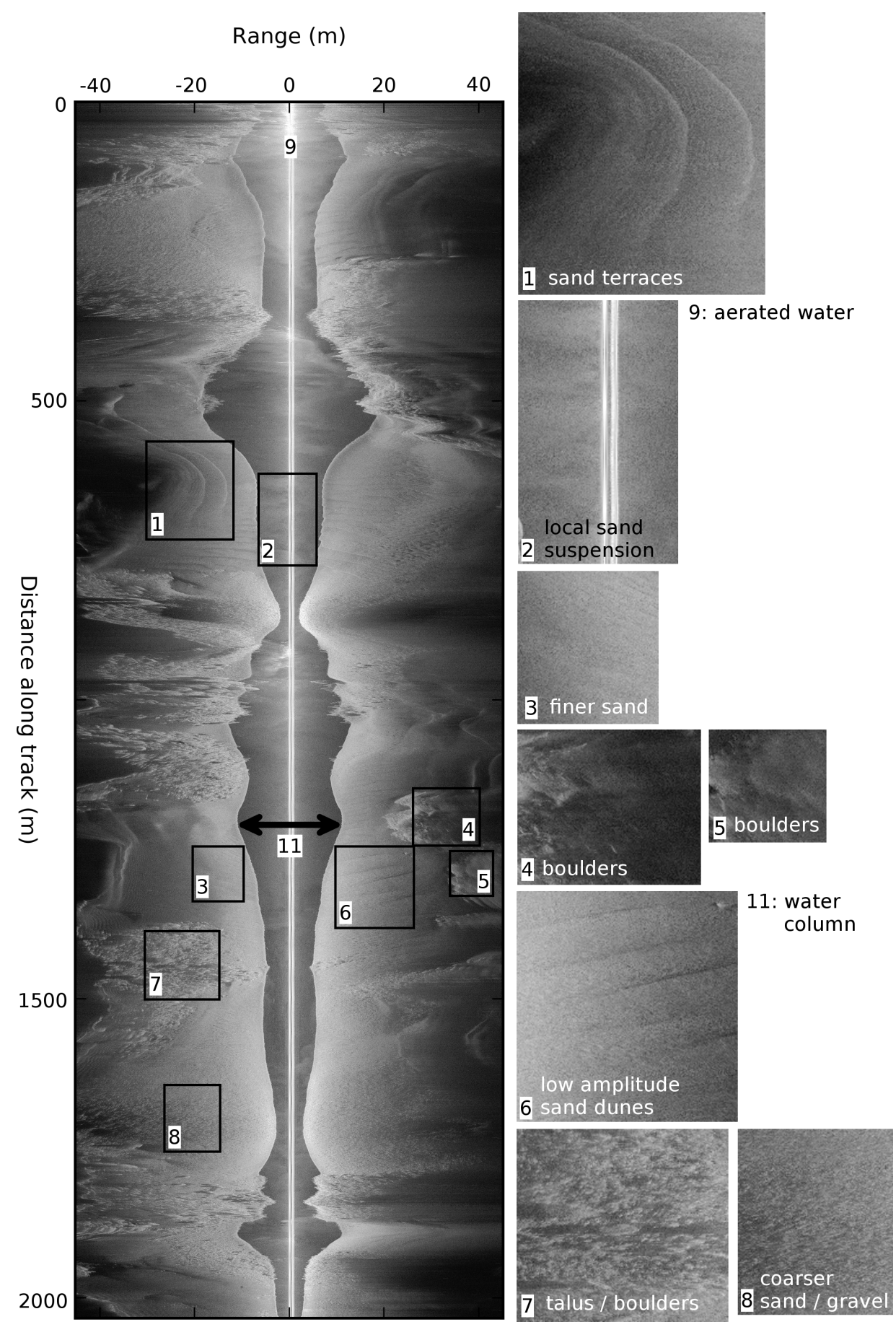

Figure 2: Raw echogram recorded during the survey depicted in Figure 1. Zero range is the instantaneous position of the transducer. Zero distance along track is the upstream extent of the survey. Some features have been annotated to aid interpretation. Light pixels represent relatively large echo receive levels. 
delay can be approximated and corrected for by approximating the slant distance covered during the delay, given by

$$
r_{t v g}=\left[c\left(\tau+\frac{3 \Delta r}{c}+\frac{\tau}{4}\right)\right]
$$

where, $\Delta r=\left(c T_{p}\right) / 2$ and for Humminbird ${ }^{\circledR}$ units, $\tau=85 \mu$ s and ping-duration $T_{p} \approx 26$ $\mu \mathrm{s}$. This distance is usually tens of centimeters. Slant-range becomes $r[m]^{\prime}=r[m]-r_{t v g}$. The horizontal distance to the $m$ th pixel is $d[m]=\sqrt{r[m]^{\prime 2}-h[n]^{2}}$, where $h[n]$ is the nadir depth below the transducer in meters, measured independently in most systems using a downward-looking singlebeam echosounder.

\subsection{Estimating bed location}

A sidescan sonar starts recording as soon as it transmits the acoustic pulse, therefore there are numerous pixels within an echogram representing the water column (Figure 2). The process of removing water column pixels from the port and starboard echograms can be reliably automated given some knowledge of sonar geometry and the time-series $h[n]$, whereby the instantaneous ( $n$ th) location of the bed-water interface, $m_{b e d}$ (in pixels), is:

$$
m_{b e d}=h[n]\left(\frac{\pi}{2}\right) \alpha_{3 d B-H}
$$

in which the horizontal angular width at half-power $\alpha_{3 d B-H}=\sin ^{-1}(c / t f)$ approximated using $f$, the frequency of sound source (in $\mathrm{Hz}$ ); and $t$, the transducer array length $(\mathrm{m})$. Some values for these parameters are given in Table 1 . Once the bed location is estimated, each swath in the echogram is redistributed proportionally to remove the water column pixels. 


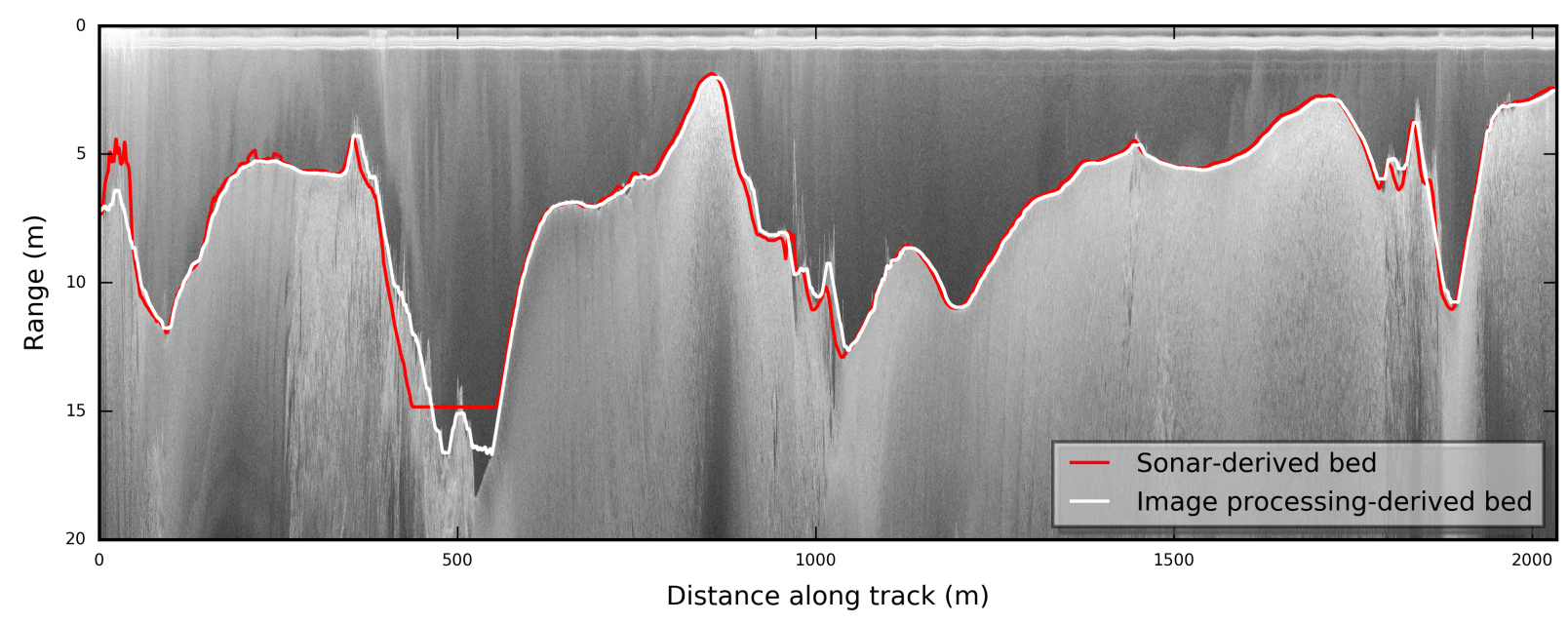

Figure 3: The first $20 \mathrm{~m}$ range of the entire $(>2 \mathrm{~km})$ portside scan, showing the sonar-derived (Equation 4) and image-processing-derived bed locations, using the algorithm described in the text. Visual inspection suggests that the latter is slightly better in this case, performing well even in the aerated water at the start of the survey (extreme left of the scan).

On occasion, the water is too turbulent or too turbid for the echosounder to provide a reliable nadir depth sounding. In such situations, the pixel location of the bed must be estimated from the echogram using image processing techniques. This study has found that a particularly effective, yet straightforward, approach to automatically find the bed-water interface in an echogram is boundary tracing using dynamic programming (Geiger et al., 1995). The assumption behind this technique is that the bed-water interface has a more similar pixel intensity than pathways through either the bed or through the water. The algorithm detailed in Sonka et al. (1993) is particularly effective and fast. The idea is to find a 'minimum-cost' path between the first $(n=1)$ and last $(n=N)$ scanline of an echogram. Cost is defined in terms of minimizing difference in pixel intensities (i.e. the pixel difference 
involved in reaching a certain pixel from another pixel). An example of sonar-derived bed location estimates (Equation 4) and the equivalent measure using the boundary tracing algorithm is shown in Figure 3.

\section{Radiometric correction of raw sidescan intensity}

\subsection{Intensity requantization}

This section concerns the correction of distortions in backscattered intensity caused by deviations from an ideal linear relationship between echogram pixel intensity and the backscattering strength of the portion of bed that it represents. The Humminbird ${ }^{\circledR}$ eight-bit echo receive-level amplitudes are converted to decibel-Watts (dB W) using

$$
S[m, n]=S[m, n]\left[10 \log _{10}(S L[n]) / 255\right]
$$

where $S L$ is the transducer source-level power in Watts. Note that the same formula would apply to any recreational-grade sonar measuring sidescan intensity as eight-bit integers. The device does not record instantaneous transducer output power, $S L[n]$, so the rootmean-square output wattage supplied by the manufacturer $(1 \mathrm{~kW})$ is necessarily used.

The above assumes a linear relationship between pixel value and received acoustic power. While the imagery obtained by the sonar is of very high quality, and similar to that of 'scientific grade' systems, the response curves of receiver voltage to echo pressure over a wide range of scattering levels is not known. Unfortunately, there is little information on the transducer specifications, in particular the degree to which a recorded voltage responds linearly to a wide range of received echo pressures. Johnson Outdoors Inc. holds patents 
on the hardware and microprocessor (Betts et al., 2010) which state that "The receiving elements are configured to amplify the signal and conducts signal filtering, base bandingrectification (e.g., remove carrier frequency), and logarithmic conversions (e.g., to obtain a wide range at output) and preferably provide variable receiver bandwidth". This suggests that a signal demodulation and band-pass filtering, to focus on signals with frequencies close to the transmit frequency, is carried out in a similar manner to a 'scientific grade' system. It is further suggested by Betts et al. (2010) that the directivity patterns of the receive arrays matches the directivity patterns of the transmit projector. It is likely that this is the case over a large range of responses, if not over the full range, which would have to be determined experimentally (Mitchell and Somers, 1989). In addition, if the quantization scheme of the sonar hardware is known more precisely, there are methods for requantization of the data to retrieve the original dynamic range of the receive levels (Blondel, 2009).

\subsection{Radiometric correction}

Radiometric correction involves compensating $S[m, n]$ for 1) the geometry of the sensortarget system (beam-angle effects); and 2) spreading/attenuation losses. Most of the energy received by the bed is reflected in the specular direction, leaving only a small proportion (usually several orders of magnitude lower) reflected back toward the sonar as backscatter. The amplitude of backscatter is a function of the physical characteristics of the water-sediment interface (micro-scale roughness, density, impedance contrast, etc.) and its geoacoustic properties which describe the intrinsic nature of the surface (composition, relative importance of volume and surface scattering for the selected frequency, etc). 


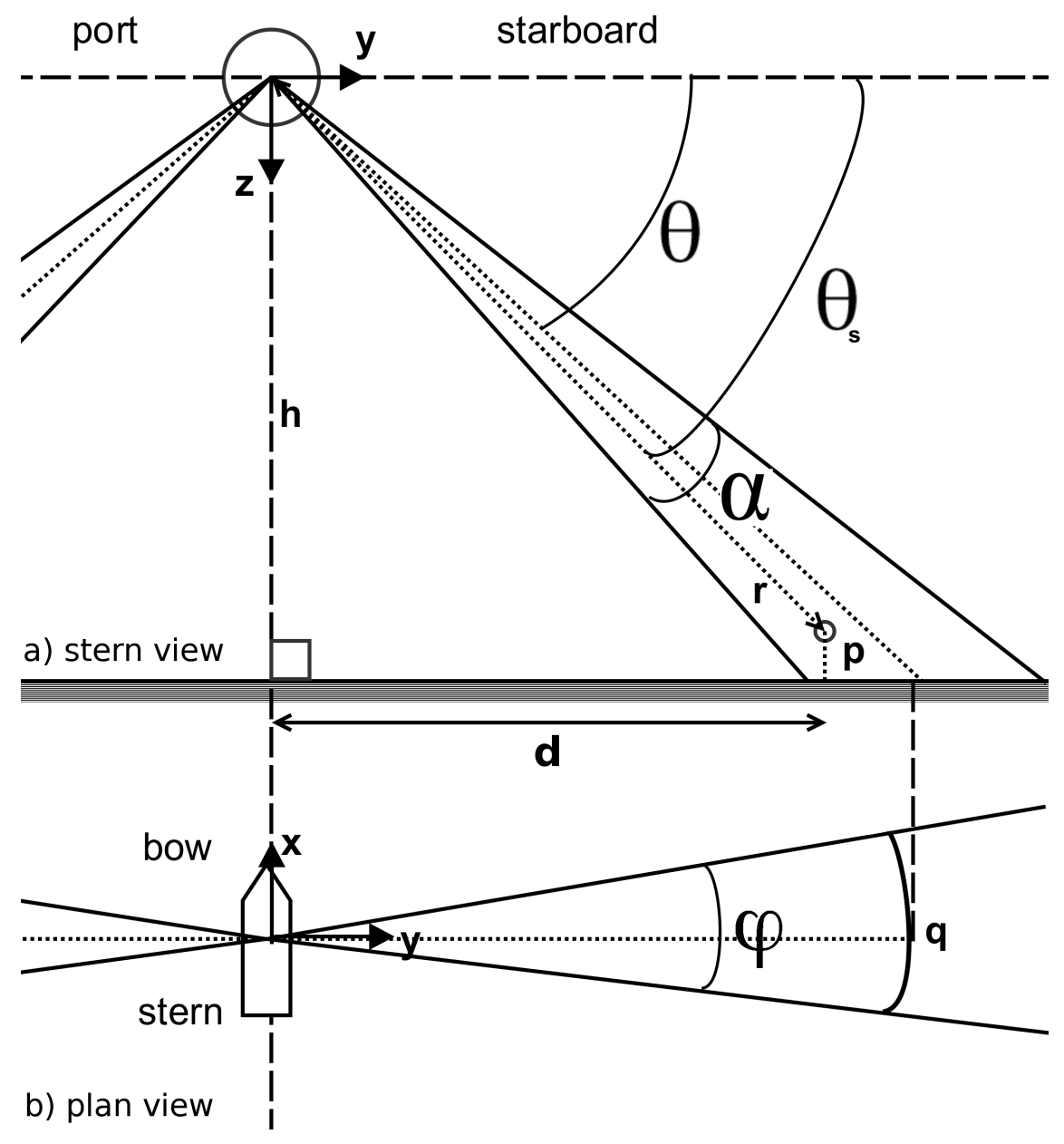

Figure 4: A simplified geometric model for a sidescan sonar, where the port and starboard facing transducers are symmetrical about the instantaneous altitude $h[n]$. Sidescan elements are angled downward at an angle of $\theta$ relative to horizontal. The angles $\alpha$ and $\phi$ are those of the beam in the $y z$ and $x y$ planes respectively. Due to $\phi$, point $p$ can be at any $x y$ position along the arc $q$, and can be expressed as the polar coordinate pair $r[m]^{\prime}$ and $\alpha_{s}$ (grazing angle), at a ground range of d. This schematic is based on Figure 2 in Burguera and Oliver (2016). 
The simplest estimate of bed backscattering strength, $B[m, n]$, from recorded receive levels $S[m, n]$, is by balancing an active sonar equation for the system (Jackson and Richardson, 2007), given by $S[m, n]=S L[n]-2 T L[m]+B[m, n]-10 \log _{10}(A[m, n])$, where all terms are in $\mathrm{dB} \mathrm{W}, T L[m]$ is the one-way transmission loss, and $A[m, n]$ is the beam footprint area. Using the terminology of Lamarche et al. (2011), an 'elementary' radiometric correction is carried out to ensure that the active sonar equation is balanced for a particular sonar system, but variations between sonar systems, due to differences in gain, $S L$, etc, between instruments, precludes a 'full calibration' which would involve measuring exact (component level) transmit levels and receive sensitivities in a standardized manner (Blondel, 2009).

Ignoring the contribution of specular reflection (cf. Lurton, 2003), concentrating only on the contribution of grazing angles $\left(\theta_{s}=\arcsin \left(h-h_{p} / r[m]^{\prime}\right)\right.$ (Figure 4), where object heights $h_{p}$ are unknown, therefore set to zero) (Jackson and Richardson, 2007; Lamarche et al., 2011), and with reference to the simple sonar sonar geometry model in Figure 4, the scattering from objects lying in an arc $q$ on the bed (Figure 4) is modeled as a Lambertian surface (Lamarche et al., 2011), which has incident sound, arriving at angle $\theta$, scattered uniformly in all directions.

The effects of sonar directivity (directionality of the beam pattern) are modeled using a cosine angular dependence in backscatter (so-called Lambert's cosine Law), which is a common approach in uncalibrated sonar systems or otherwise when the beam shape is imprecisely known, and especially when bed slopes are unavailable (Lurton, 2003; Jackson and Richardson, 2007). Following Burguera and Oliver (2016), the echo intensity $S[m, n]$ returned by a point on the bed $p=\left(r[m]^{\prime}, \theta_{s}\right)$ is modeled as: 


$$
S[m, n]=K \cdot \Omega[m, n] \cdot B[m, n] \cdot \cos \left(\theta_{s}\right)
$$

where under a flat bed assumption $\theta_{s} \approx \theta\left(\theta=35\right.$ degrees for a $455 \mathrm{kHz}$ Humminbird ${ }^{\circledR}$ transducer (Betts et al., 2010)), $K$ is a normalization constant, $B[m, n]$ is the bed backscattering strength. Ensonification intensity $\Omega[m, n]$ is modeled as (Kleeman and Kuc, 2008) (for a flat bed case):

$$
\Omega[m, n]=\frac{M f a^{4}}{r[m]^{\prime 2}}\left(\frac{2 J_{1}\left(\frac{2 \pi}{\lambda} a\right)}{\frac{2 \pi}{\lambda} a}\right)^{2}
$$

where $M$ is a constant of proportionality, $J_{1}$ is a first-order Bessel function of the first kind, $f$ and $\lambda$ are the frequency $(\mathrm{Hz})$ and sound wavelength (m), respectively, and $a$ is the radius of a transducer element which following Burguera and Oliver (2016) is approximated using $a=0.61 \lambda /(\alpha / 2)$ where $\alpha$ (the opening angle in the $z y$ plane, Figure 4$)$ is the vertical angular beam width at half power (Table 1). Rearranging Equation 6, instantaneous backscatter strength may be expressed (Burguera and Oliver, 2016):

$$
B[m, n]=(K \cdot M)^{-1} \frac{S[m, n]}{\Omega[m, n] \cdot \cos \left(\theta_{s}\right)}
$$

Transmission losses (spherical spreading plus attenuation losses in the water) are estimated using

$$
T L[m]=40 \log _{10}\left(r[m]^{\prime}\right)+2 \frac{\kappa}{1000} r[m]^{\prime}
$$

where $\kappa=\kappa_{w}+\kappa_{s}\left(\mathrm{~dB} \mathrm{~W} \mathrm{~km}{ }^{-1}\right), \kappa_{w}$ is an attenuation constant which depends on the 
frequency of the transducer (Jackson and Richardson, 2007), the celerity of sound in water, salinity and temperature, calculated using standard formulas (e.g. Buscombe et al., 2014a). If suspended sediment concentrations and grain sizes are known, sediment attenuation $\kappa_{s}$ can be estimated using established methods (e.g. Urick, 1948).

A simple approximation for instantaneous acoustic footprint is $A[m, n] \approx \Delta x[m] \Delta y[n]$. Along-track pixel, $\Delta x[m]$, is a function of the horizontal width of the sonar beam pattern, and is computed using (Blondel, 2009):

$$
\Delta x[m]=d[m] \sin \alpha_{3 d B-H}
$$

Across-track pixel size, $\Delta y[n]$, is typically several times smaller than $\Delta x[m]$ and is a function of the effective pulse length, $\tau$, of the sonar transmitter, and the local grazing angle $\beta$ (which is usually unknown, in which case $\beta=0)$ :

$$
\Delta y[n]=\left(\frac{c \tau}{2}\right)\left(\frac{1}{\cos \beta}\right)
$$

The slant-range and radiometrically corrected version of the scan shown in Figure 2 is presented in Figure 5A. At this stage, if the echogram is noisy, the automatic phasepreserving filtering approach of Kovesi (2012) has been found to be particularly effective (Figure 5B) at noise removal. The method, designed with geophysical imaging particularly in mind, is based on computing local amplitude and phase values across the scan using monogenic filters, implemented using a second-order high-pass Butterworth filter. Trials with several scans have shown that a good choice for cutoff spatial frequency for the high 


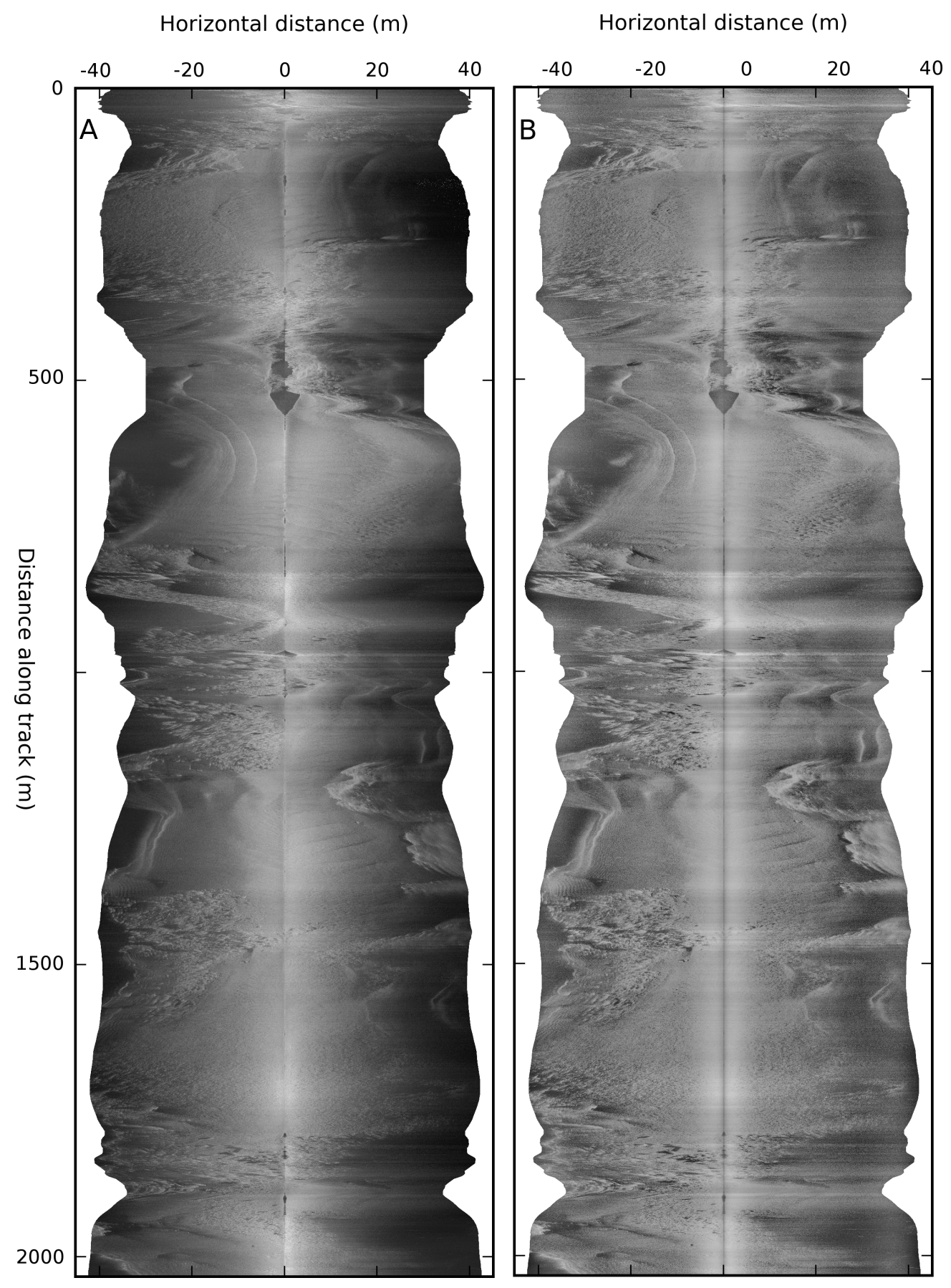

Figure 5: A) The echogram presented in Figure 2 which has been slant-range corrected, re-quantized to a dB W scale (Equation 5), and corrected for directivity, transmission losses, and beam footprint. B) The radiometrically corrected echogram presented alongside in A which has been filtered using the phase-preserving denoising algorithm of Kovesi (2012). 
pass filter (see discussion in Kovesi $(2012)$ ) is $6 / N$, but that optimal frequencies may lie in the range $10 / N$ to $2 / N$ depending on the data.

\section{Removal of sidescan echogram acoustic shadows}

Processing sidescan data from shallow water environments often requires removing large acoustic shadows in the lee of banks, shallow channel margins (Figure 2), and other large obstructions. These shadows are low intensity and essentially devoid of texture, except for that caused by signal noise. Therefore, a simple approach to their automated segmentation on a threshold intensity alone is often sufficient for an individual scan. However, defining a more widely applicable intensity threshold is inappropriate owing to variation in acoustic shadow intensities within scans (compare, for example, the intensities of the shoreline-induced shadows in Figure 2) and between scans.

This study has found that a robust approach to automated segmentation of the echogram into two classes ('shadow', $S_{0}[m, n]$, and 'not shadow', $S_{1}[m, n]$ ) is to use standard spatialdomain texture metrics. The radiometrically corrected echogram is partitioned into small windows, and the data in each is analyzed using a grey-level co-occurrence matrix (GLCM), which is a histogram of co-occurring discrete values over a range of offsets (Haralick, 1979). GLCM functions characterize the texture of an image by calculating how often pairs of pixels with specific values and at a specified spatial offset occur. We compute the GLCM for up to 256 grey levels and over five pixel offsets, each for small windows of echogram in order to characterize spatial heterogeneity. The windowing procedure is similar to that described by Buscombe et al. (2014a) for a different purpose (multibeam backscatter analysis). There 


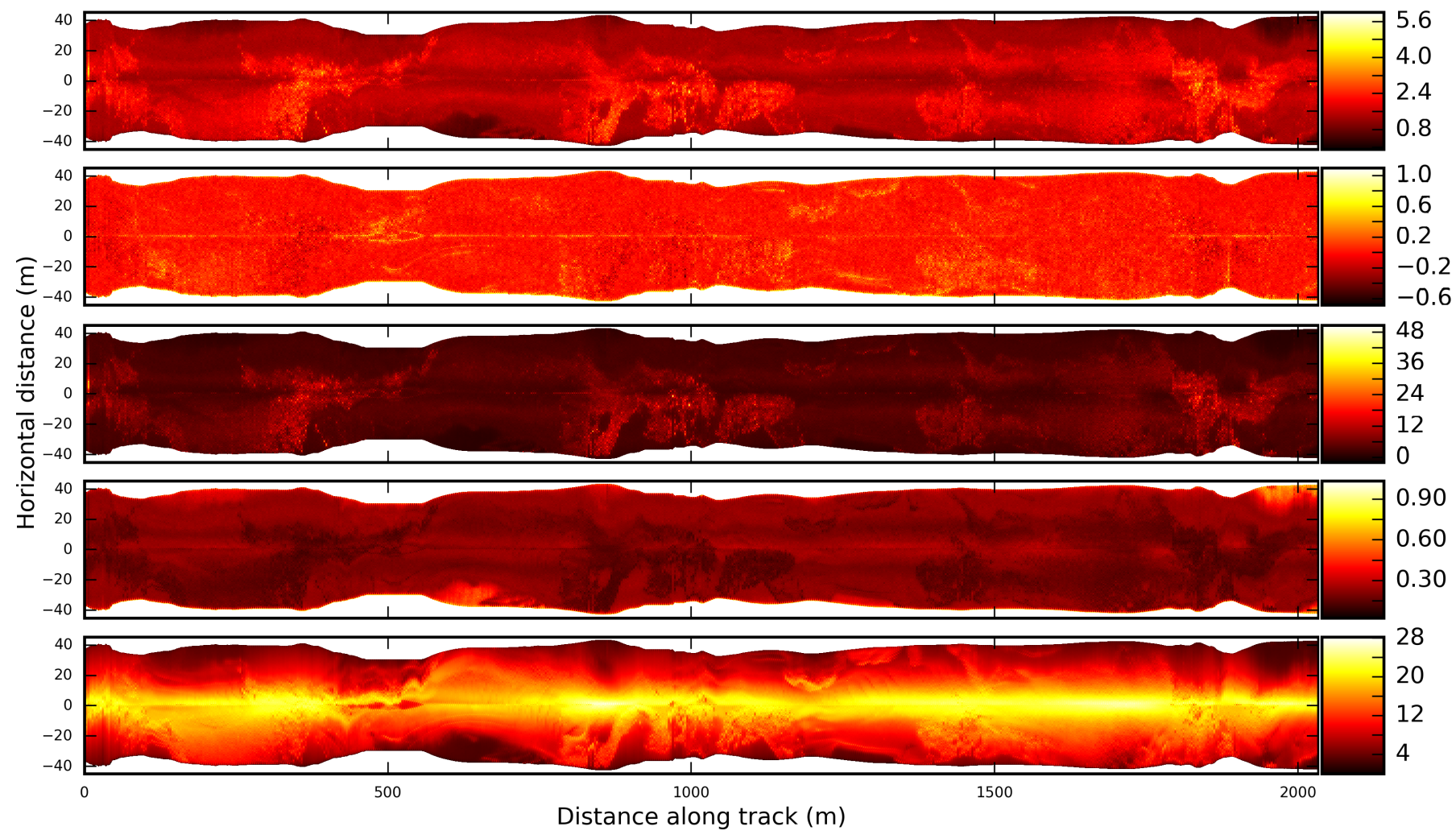

Figure 6: Input parameters for the shadow removal procedure expressed in Equation 12. From top to bottom: dissimilarity $G$, correlation $C$, contrast $K$, energy $E$, and mean intensity $\bar{S}$. All but the last parameter is calculated from a GLCM analysis on a small window of data (in this case, 31 square pixels). Notice how the spatial patterns of $G, K$ and $E$ appear to be closely related to areas of coarse and fine textures in the merged port and starboard scan shown in Figure 5A. 
are a number of derived (second order, or 'neighborhood') statistical parameters that can be computed from each GLCM matrix (Haralick, 1979) that are related to different aspects of echogram 'texture', of which 'dissimilarity', $G$, 'correlation', $C$, 'contrast', $K$, and 'energy', E, (Reed and Hussong, 1989) were collectively found to be most useful for identifying acoustic shadows among several analyzed echograms with noticeably different textural characteristics. Each of these parameters are shown in Figure 6, along with mean (per window) sidescan intensity $\bar{S}$ (in $\mathrm{dB} \mathrm{W}$ ). The following equation for a shadow seems to hold well for most echograms analyzed to date:

$$
S_{0} \subset S[m, n]:(G<3) \cup(C<0.2) \cup(K<8) \cup(E>0.15) \cup(\bar{S}<6)
$$

which is followed by morphological reconstruction operation (Soille, 2013), which fills small 'holes' in the binarized image. This shadow area is removed from the echogram (Figure 7). The relative importance of the terms in Equation 12 depend on the distributions of textures and intensities, hence the need for a union of multiple binary operations.

\section{Mapping sidescan intensity}

\subsection{Positioning and vessel attitude}

Backscattered amplitudes are represented by pixels that are displayed as a function of horizontal range in a raster format $(S[m, n])$. However, the projection on the bed of the transmitted pulse dictates that the aspect ratio of a pixel (i.e. the along-track to acrosstrack ratio) increases away from nadir (Cervenka et al., 1994). The anamorphic distortion this creates when mapping scanlines into geographic rasters with square pixels over large 


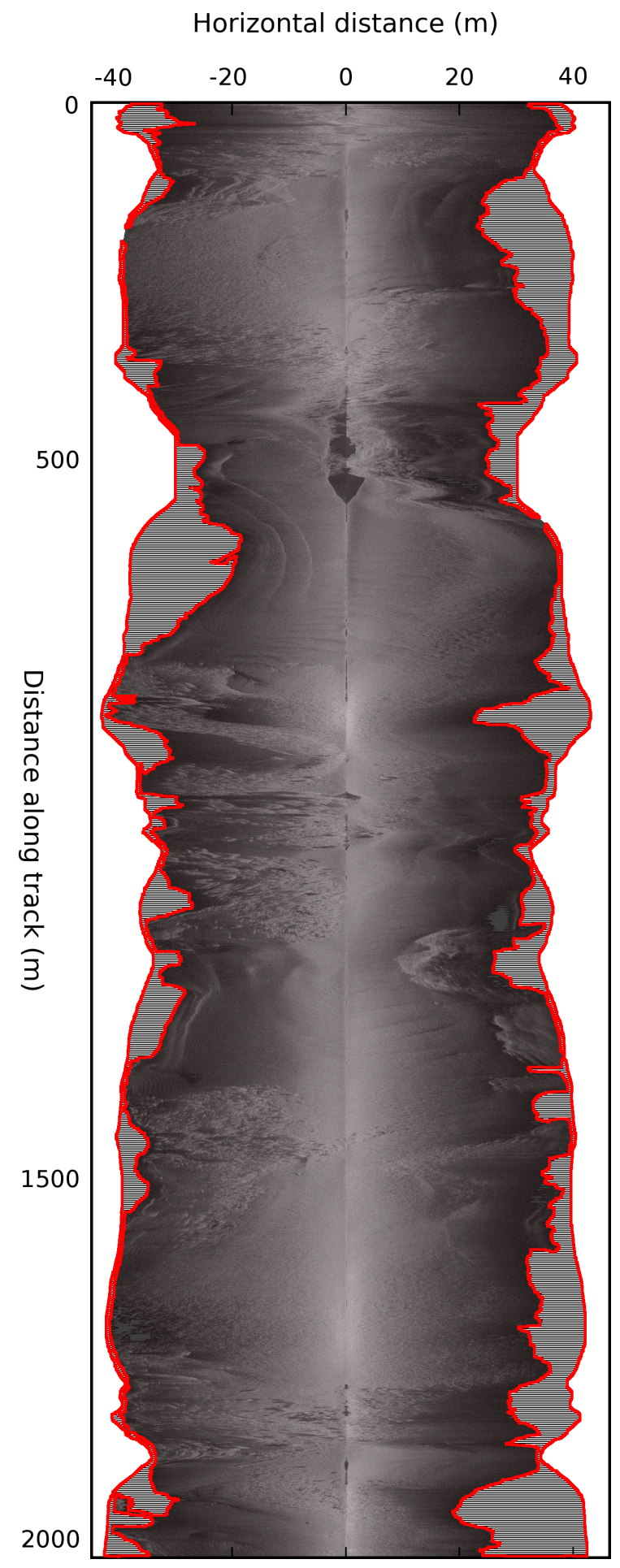

Figure 7: Merged echogram, with shadows identified following the automated procedure expressed in Equation 12. 
distances, is small enough in shallow water (hence relatively small horizontal scan extents of the order tens of meters rather than up to thousands of meters possible in deep water) that it is ignored without significant degradation of the sidescan image. Therefore, in the interests of simplicity in the following, no attempt is made to correct for anamorphism, the procedures for which have been described elsewhere (e.g. Cervenka and De Moustier, 1993).

Humminbird ${ }^{\circledR}$ positions are reported as coordinates, $[X[n], Y[n]]$, in a World Mercator Meters coordinate system (EPSG code 3395, with no UTM zone). These coordinates are converted to decimal degrees. The following conversion is applied for latitude:

$$
\Phi[n]=\tan ^{-1}\left[\tan \left(2 \tan ^{-1}\left(e^{Y[n] / R}\right)-\frac{\pi}{2}\right)(1+2 F)\right]\left(\frac{180}{\pi}\right)
$$

and longitude is given by:

$$
\lambda[n]=\frac{X[n](180 / \pi)}{R}
$$

where, using the NAD83/WGS84 Datum, $R=6378137 \mathrm{~m}$ is the equatorial radius of the Earth, and $F=1 / 298.257223563$ is the flattening parameter. Geographic coordinates $[\Phi[n], \lambda[n]]$ are then converted to a projected coordinate system using standard cartographic projection libraries (Evenden, 1990). Time-series of instrument heading, $\Theta[n]$ can be calculated using bearing between successive WGS84 decimal degree coordinates $\left[\Phi\left[n_{-} 1\right], \lambda\left[n_{-} 1\right]\right]$ and $[\Phi[n]$, $\lambda[n]]$ using:

$$
\Theta[n]=\tan ^{-1}\left(\frac{\cos \Phi\left[n_{-} 1\right] \sin \Phi[n]-\sin \Phi\left[n_{-} 1\right] \cos \Phi[n] \cos \lambda[n]-\lambda\left[n_{-} 1\right]}{\sin \lambda[n]-\lambda\left[n_{-} 1\right] \cos \Phi[n]}\right)
$$


which is a course-over-ground (COG) compass heading from True north in the East-NorthUp (ENU) coordinate reference frame. To convert this into a more conventional (for sonar) North-East-Down (NED) coordinate reference frame, the radian phase $(\Theta[n]-\pi / 2)$ is 'unwrapped' by changing absolute differences greater than $\pi$ to their $2 \pi$ complement. To avoid gaps in sonar coverage during data acquisition, the maximum velocity of the transducer, $v_{\max }$ can be computed using

$$
v_{\text {max }}=c\left[\cos \alpha_{V \max } \tan \alpha_{V \min } \tan \alpha_{3 d B-H}\right]
$$

which, given the values in Table 1 , in freshwater $\left(c=1450 \mathrm{~ms}^{-1}\right)$ operating at $455 \mathrm{kHz}$ equates to $0.825 \mathrm{~ms}^{-1}$, and in in saltwater $\left(c=1500 \mathrm{~ms}^{-1}\right)$ operating at $800 \mathrm{kHz}$ equates to $1.004 \mathrm{~ms}^{-1}$.

\subsection{Georectification}

The process of georectifying an echogram involves calculating the position of each sidescan pixel to place the echogram into a known coordinate system. This is distinguished from orthorectification which would involve correction for distortions due to bathymetric variation (Cervenka et al., 1994). Below is a simple procedure for estimating each scanline pixel location by formulating a mapping from echogram image coordinates (along-track distance and horizontal/across-track range) to real-world projection coordinates, given an estimate of the instantaneous location of the sonar, and a modeled sonar geometry and radiation pattern, without a known bathymetry, using a flat horizontal bottom assumption (see section 2.2). This is designed to map pixels as close as possible to their true geographic location, rather than to use this information for further radiometric correction of the instantaneous 
backscatter. It is important to note that the procedures described below differ from previous approaches to mapping low-cost sidescan data such as those described by Kaeser and Litts (2010) and Kaeser et al. (2013), and those within currently available commercial software. A 'point cloud' of sidescan intensity in a metric coordinate system is produced, rather than a more approximate projection of scans as raster grids or images, referenced to vectors of slant- or ground-range and distance (corrected or uncorrected by instantaneous vessel speed), based on rubber sheeting or a similar affine or perspective transformation between scan and real-world coordinate systems. In this way, the data are more amenable to further analysis on the point cloud, such as roughness calculations (Buscombe, 2016), and analyses involving point-to-point distances and orientations, as well as in a more natural form for uncertainty estimates in scan pixel locations based on imprecise sonar location information, and a lack of information on bathymetry and boat attitude. It also aids mosaicking of overlapping scans, because point clouds can be merged and interpolated onto a regular grid according to weightings assigned by intensity, position of each point relative to the sonar, or other geometric arguments.

Following the definition of the echogram according to section 2.1, we further define the horizontal position of the $n$th line of the echogram as $[x[n], y[n]]$ and the intersection of the beam with the bed defines the point $\left[x_{0}[n], y_{0}[n]\right]$. In which case, ignoring the effects of pitch, 


$$
\begin{aligned}
& x_{s}[m, n]=x_{0}[n]+m\left(r^{\prime}\right) \cos \Theta[n] \\
& y_{s}[m, n]=y_{0}[n]+m\left(r^{\prime}\right) \sin \Theta[n]
\end{aligned}
$$

(Cobra et al., 1992) where

$$
m\left(r^{\prime}\right)=\sqrt{\left(m\left[\frac{\pi}{2} \alpha_{3 d B-H}\right]\right)^{2}-h[n]^{2}}
$$

A Taylor-series expansion of (17) yields, where $v[n]$ is the speed of the transducer, and $T[n]$ is the duration of the $n$th ping, and with no transducer attitude instabilities:

$$
\begin{array}{r}
0=\Delta_{n} x_{s}[m, n] \approx \Delta x_{0}[n]+m\left(r^{\prime}\right) \sin \Theta[n] \Delta \Theta[n] \\
v[n] \cdot T[n]=\Delta_{n} y_{s}[m, n] \approx \Delta y_{0}[n]+m\left(r^{\prime}\right) \cos \Theta[n] \Delta \Theta[n]
\end{array}
$$

It follows that vectors of arbitrary positions in the scan can simply be described as a rotation around the center scan point, $\left[E_{0}[n], N_{0}[n]\right]$, to arrive at the coordinates of the entire scan in a projected coordinate system, i.e. $\left[x_{s}, y_{s}\right] \rightarrow\left[E_{s}, N_{s}\right]$, using:

$$
\begin{array}{r}
E_{s}[m, n]=(h[n] \sin \Theta[n])+E_{0}[n]-\cos \Theta[n] \\
-\left(m\left(r^{\prime}-N_{0}[n] \sin \Theta[n]\right)\right. \\
N_{s}[m, n]=(h[n] \cos \Theta[n])+N_{0}[n]-\sin \Theta[n] \\
+\left(m\left(r^{\prime}-N_{0}[n] \cos \Theta[n]\right)\right.
\end{array}
$$


The point cloud in a projected coordinate system, $S\left[E_{s}, N_{s}\right]$, distributed unevenly in the plane, is gridded to the surface $S[\mathbf{X}]$, where coordinate vector $\mathbf{X}$ ranges over a regular orthogonal two-dimensional lattice grid $\left[E_{s}, N_{s}\right], E_{s}=\left[\min \left(E_{s}\right): \iota: \max \left(E_{s}\right)\right]$, and $N_{s}=$ $\left[\min \left(N_{s}\right): \iota: \max \left(N_{s}\right)\right]$. Gridding resolution, $\iota$, is informed by along-track resolution, $\Delta x[m]$ (Equation 10). Given that a wide range in $\Delta x[m]$ usually exists, gridding requires $\iota \geq \min (\Delta x[m])$

Nearest-neighbor gridding is a computationally effective means with which to grid data with high spatial density, without interpolation artifacts. An average value is assigned to each grid node that have $k(k \geq 1)$ points ('neighbors') within a radius $\rho$ centered on the node. The average value is computed as a weighted mean (using weighting function $w)$ of the nearest point at $\delta_{\rho}$ distance from the node. A simple nearest neighbor with no weighting produces sidescan maps with no interpolation artifacts and few apparent survey artifacts (Figure 8). Various possible weighting functions, such as inverse-square-distance to grid node, $w(\rho)=1 /\left(1+\delta^{2}\right)$, where $\delta=3 \delta_{\rho} / \rho$, or Gaussian $e^{-\delta^{2} / \sigma}$, where $\sigma$ is a standard deviation (in meters: higher $\sigma$ smooths over a larger radius) yield similar, also suitable, albeit more smooth maps (not shown). Similar weighting functions can be designed to create a mosaic of overlapping scans, based on intensity, grazing angle, or proximity to the sonar.

\section{Characterizing benthic substrates through sidescan texture analysis and au-}

\section{tomated segmentation}

Spatially distributed benthic habitat delineation has become a global aquatic science priority (e.g. Diaz et al., 2004; Costello, 2009) whereby distinct geological, geomorphological 


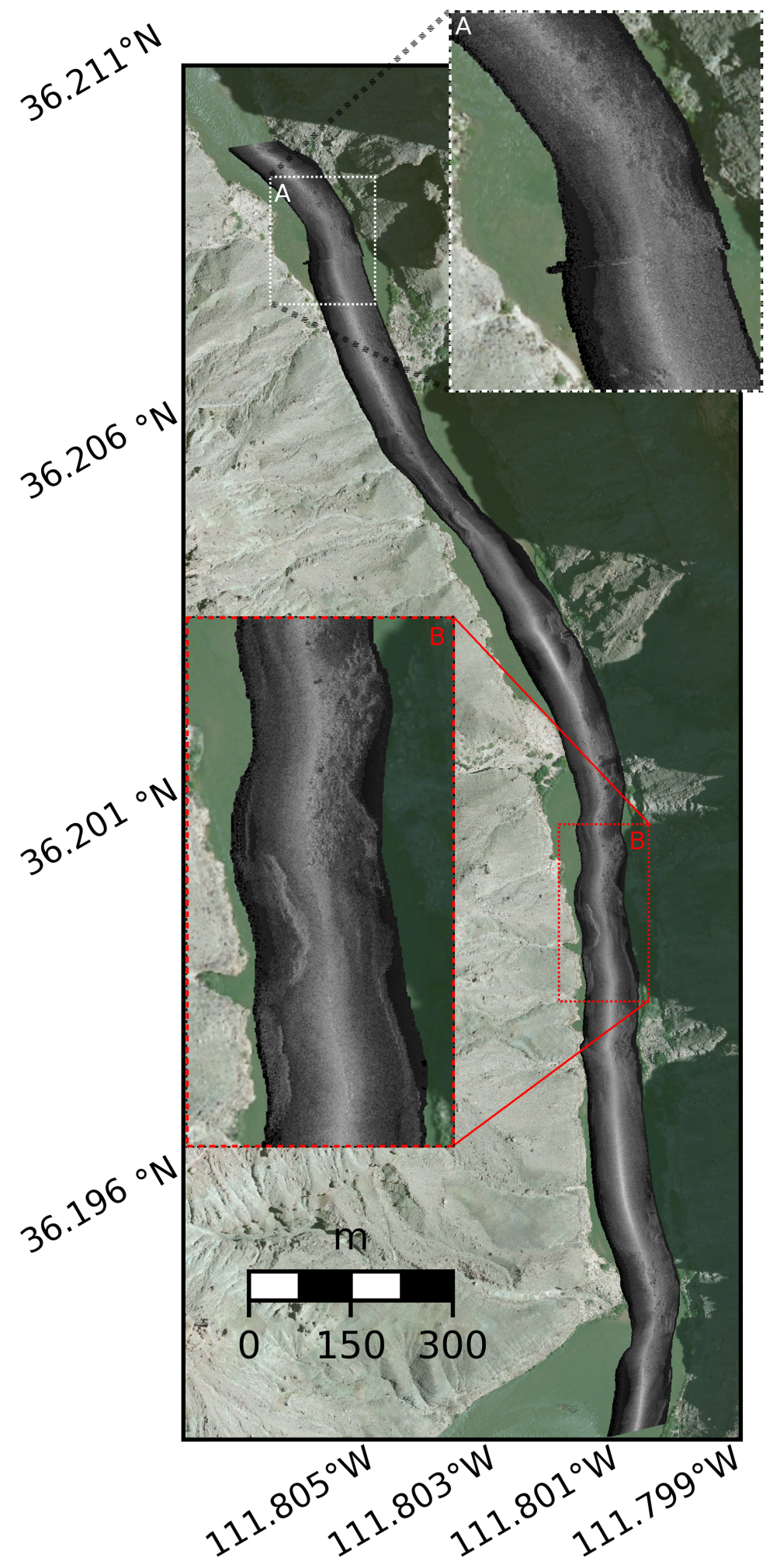

Figure 8: Simple $k=1$ nearest neighbor grid of the scan presented in Figure 7, using a grid resolution of $0.25 \times 0.25 \mathrm{~m}$, with a search radius of $1 \mathrm{~m}$, and 34 with no weighting function. 
and eco-hydraulic regions are interpreted to formulate physical habitat models which can be used to model spatial distributions of benthic biology (e.g. Ryan et al., 2007; Muñoz-Mas et al., 2014; Frieden et al., 2014), and fluid stresses exerted on the bed. An increasingly common means to map benthic habitats in shallow water is through use of swath sonar data (e.g. Brown et al., 2011). The almost photo-realistic acoustic images of the bed provided by sidescan sonar make them ideally suited for the identification and interpretation of bed features aiming at the classification of shallow-water benthic physical habitat. Some studies even report a correlation between sidescan intensity and grain size (e.g. Goff et al., 2000; Collier and Brown, 2005) although this is unlikeley to be universally true. Therefore, segmentation of acoustical imagery into discrete patches is often carried out either through visual analysis (e.g. Kennish et al., 2004; Diaz et al., 2004; Kaeser et al., 2013), or automated methods (e.g. Amiri-Simkooei et al., 2009; Buscombe et al., 2014b, 2015).

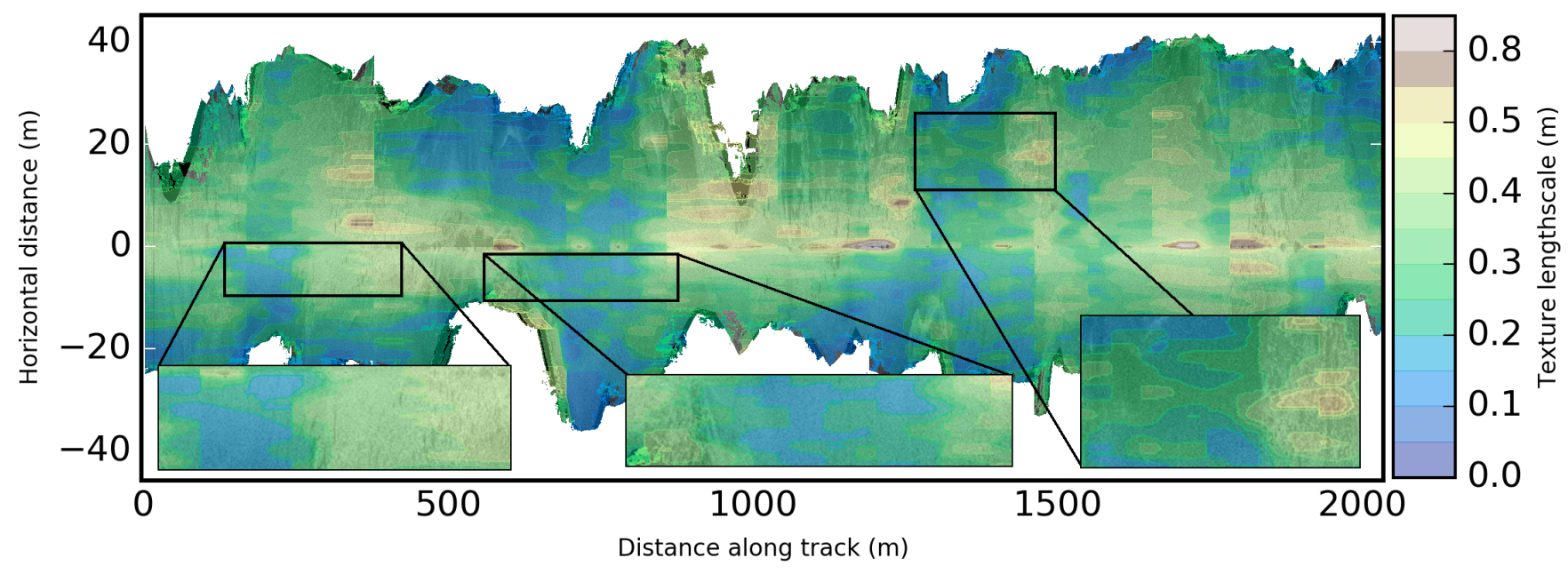

Figure 9: Filled-contours of 'texture lengthscales' (in meters) computed according to the method of Buscombe et al. (2015), overlying the merged sidescan echogram. 
Sidescan surveys typically cover tens or hundreds of square kilometers, therefore interpretation of sidescan sonar imagery by eye is very time-consuming, as well as being prone to subjectivity. Various approaches to automatic identification and segmentation of sedimentological characteristics or benthic habitat have been proposed (e.g. Atallah et al., 2002; Collier and Brown, 2005). Buscombe et al. (2015) proposed a method for automated, physically based sidescan echogram texture segmentation using windowed wavelet analysis. The method estimates the spatially explicit 'texture lengthscale' (in meters), which is a statistical representation of the average length between texture elements, that integrates over many attributes of bed texture. The textural lengthscale is not a direct measure of grain size, rather a statistical measure of texture which accounts for the effects of sonar geometry (the dependence of local sidescan intensity contrast on sonar geometry, particularly grazing angle of the incident beam). The technique is a means to automatically quantify texture in echograms, in a spatially explicit sense, using objective analyses with roughness expressed as a lengthscale. The application of the method to the example data set results in a spatial distribution closely correlated with sidescan textures identifiable by eye (Figure 9). When mapped according to the same method as outlined above in section 7.2 , but using spatially distributed (per pixel, $[m, n]$ ) texture lengthscales instead of sidescan intensity, then contoured, the result (Figure 10) is a high-resolution map of automatically segmented regions according to an physically intuitive measure of texture (bed roughness) magnitudes on a linear scale (see also examples in Buscombe et al. (2015) and Hamill et al. (2016)). The relationship between these texture lengthscales and substrates and bed structures in a variety of physical habitats is the subject of ongoing research. 


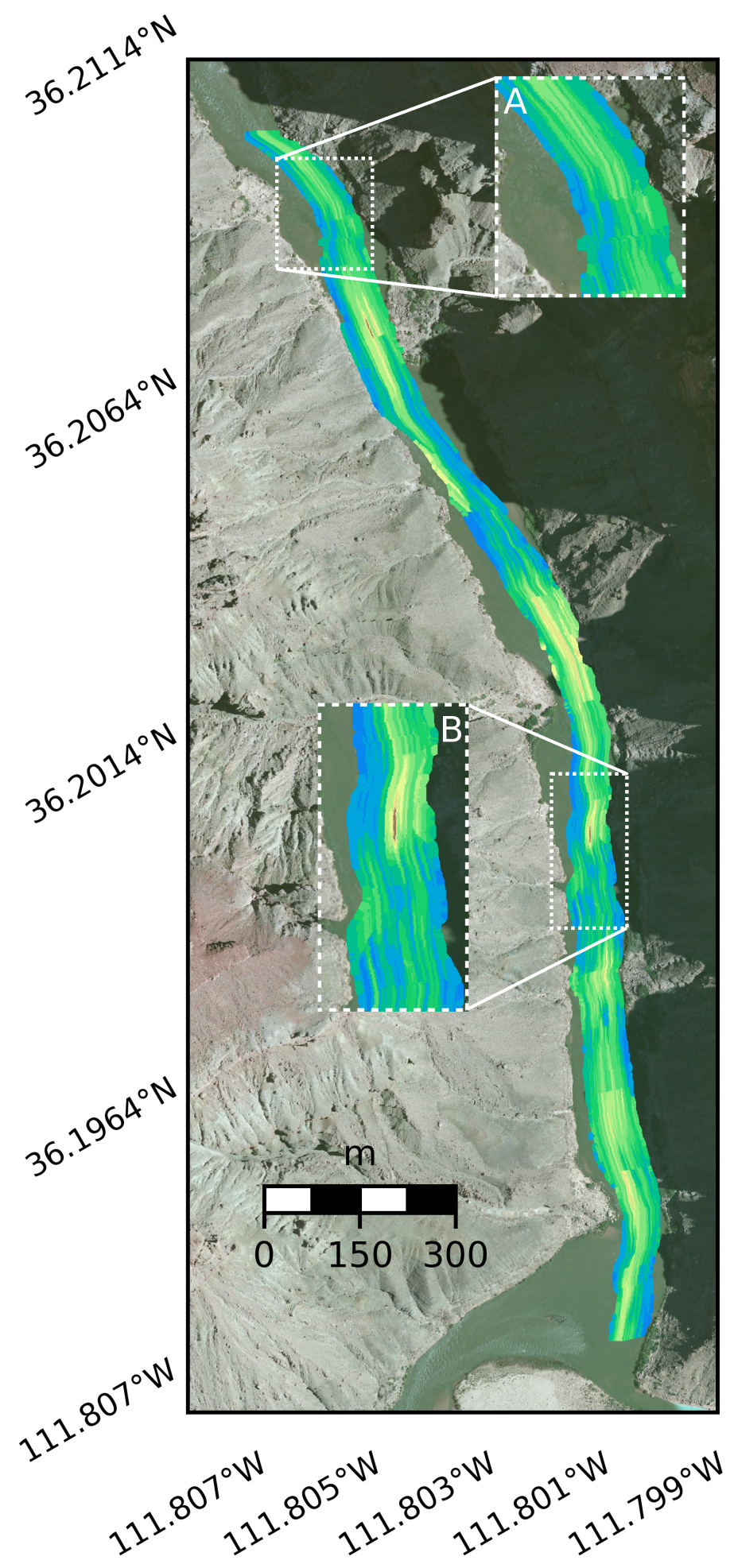

Figure 10: Filled-contour map derived from a simple $k=1$ nearest neighbor grid of the texture lengthscales presented in Figure 9, using a grid resolution of $0.25 \times 0.25 \mathrm{~m}$, with a search radius of $1 \mathrm{~m}$, and with no weighting function. The contour levels used are identical to those used in Figure 


\section{Characterizing benthic substrates through full-waveform ('echo shape') anal- ysis of singlebeam echosounder data}

As well as sidescan echograms, recreational grade sidescan sonar systems also record the echogram, $D[n, i]$, from a singlebeam echosounder (section 2.1). The use of acoustical analyses on data from the normally incident (nadir beam) singlebeam echosounder data, in order to automatically discriminate between substrate types, is fairly widespread (e.g. Burns et al., 1989; Kenny et al., 2003; Collier and Brown, 2005; Brown et al., 2011; Amiri-Simkooei et al., 2011). The basic idea is to measure the intensity of the envelope of return echoes from the bed and multiples of that return. With appropriate ground-truth calibration for a particular environment or substrate type, and a means to statistically classify (supervised or unsupervised) derived echo parameters, this family of methods has met with some success (e.g. Amiri-Simkooei et al., 2011; Brown et al., 2011; Serpetti et al., 2011; Hamilton, 2014). Some commercially available products such as the RoxAnn ${ }^{\mathrm{TM}}$ (Sonavision Ltd, UK) and QTC Multiview $^{\text {TM }}$ (Questor Tangent Corp, Canada) are also available to carry out similar analyses.

Below, a simple version of the method proposed by Burns et al. (1989) is modified for use with data from a Humminbird ${ }^{\circledR}$ downward-looking echosounder, under the assumption that there is no transducer gain or other receive-signal filters, and ignoring the contribution of noise (which in this situation is difficult to estimate). The volume backscattering strength, $S_{v}[n, i]\left(\mathrm{dB} \mathrm{re} \mathrm{m}^{2} / \mathrm{m}^{3}\right)$, as the ratio of backscatter intensity from a unit volume, expressed as a nominal distance of $1 \mathrm{~m}$ from the incident sound source (Jackson and Richardson, 2007) 
is approximated using

$$
S_{v}[n, i]=D[n, i]+20 \log _{10} r^{\prime}[i]+2 \kappa r^{\prime}[i]+10 \log _{10}\left(\frac{S L \lambda^{2} c \tau \psi}{32 \pi^{2}}\right)
$$

where $r^{\prime}[i]=r[i]-r_{\text {tvg }}, \lambda=c / f, \psi=5.78 /(k a)^{2}$ (Urick, 1967) is the solid angle of the beam (Table 1 ), where acoustic wavenumber $k=2 \pi / \lambda$, transducer radius is approximated as $a=1.6 /(k \sin \Psi / 2)$ and $\Psi$ is the angular beamwidth at half power. All other terms are defined in the sections above.

The envelope of returns of the first echo, $E 1$, from the bed, defined by pixel locations $E 1\left[i_{\text {start }}\right]$ and $E 1\left[i_{\text {end }}\right]$, is constrained by the sonar geometry and ping duration $T_{p}$, such that:

$$
\begin{gathered}
E 1\left[i_{\text {start }}\right]=\left(\frac{2 \pi^{-1} d[n] \alpha_{3 d B-H}}{c}\right) 2 T_{p}^{-1}+2 \pi \alpha_{3 d B-H} \\
E 1\left[i_{\text {end }}\right]=E 1\left[i_{\text {start }}\right]+3 \nu
\end{gathered}
$$

where the near-field region $\left(\nu=t^{2} / 4 \lambda\right)$ is the distance within which the energy within the beam is not a simple inverse-square function of range (Blondel, 2009). The second echo envelope, E2, is resultant from a transducer-bed-water surface-bed-transducer path, therefore is defined by pixel locations $E 2\left[i_{\text {start }}\right]$ and $E 2\left[i_{\text {end }}\right]$ at twice the survey depth

$$
\begin{gathered}
E 2\left[i_{\text {start }}\right]=2\left(\frac{2 \pi^{-1} d[n] \alpha_{3 d B-H}}{c} 2 T_{p}^{-1}\right) \\
E 2\left[i_{\text {end }}\right]=E 2\left[i_{\text {start }}\right]+3 \nu
\end{gathered}
$$


An illustration of a raw echogram from the $200 \mathrm{kHz}$ downward-looking echosounder, $D[n, i]$, from our example data set, and the locations of the envelopes associated with the first and second peaks, using the above relations, is presented in Figure 11. The energy within the first peak of the $n$th ping is the integral of the volume backscattering strength $S_{v}[n, i]$ multiplied by the scattering cross section:

$$
e_{1}=4 \pi \cdot 1852^{2} \int_{E 1\left[i_{\text {start }}\right]}^{E 1\left[i_{\text {end }}\right]} 20 \log _{10}\left(S_{v}[n, i]\right)
$$

which has nominal units $\mathrm{m}^{2} / \mathrm{m}^{3}$. For historical reasons, the SI unit for scattering cross section is based on the nautical mile $(1852 \mathrm{~m})$. This parameter is variously known as the $e_{1}$ coefficient or 'roughness' parameter (e.g. Kenny et al., 2003). The energy within the second peak is calculated in an identical manner to Equation 26 using pixel locations $E_{2}$, resulting in the $e_{2}$ coefficient or 'hardness' or 'impedance' parameter. In reality, $e_{1}$ and $e_{2}$ are simply acoustic parameters whose relationship to bed roughness and hardness, respectively, is not universal (Hamilton, 2014), requiring site-specific calibration (e.g. Hamilton et al., 1999; Serpetti et al., 2011).

Like the method outlined in section 8, this approach might find widespread and general utility for physically-based bed substrate characterization in a variety of aquatic environments. For example, using the example data set (Figure 11) a map of $e_{1}$ and $e_{2}$ coefficients (Figure 12) reveal an interesting spatial pattern in bed characteristics that seem to be related to the proximity of tributary debris fans, which are a local source of coarse sediment input to the river. A simple $k$-means clustering of the $e_{1}$ and $e_{2}$ data into three statistical 


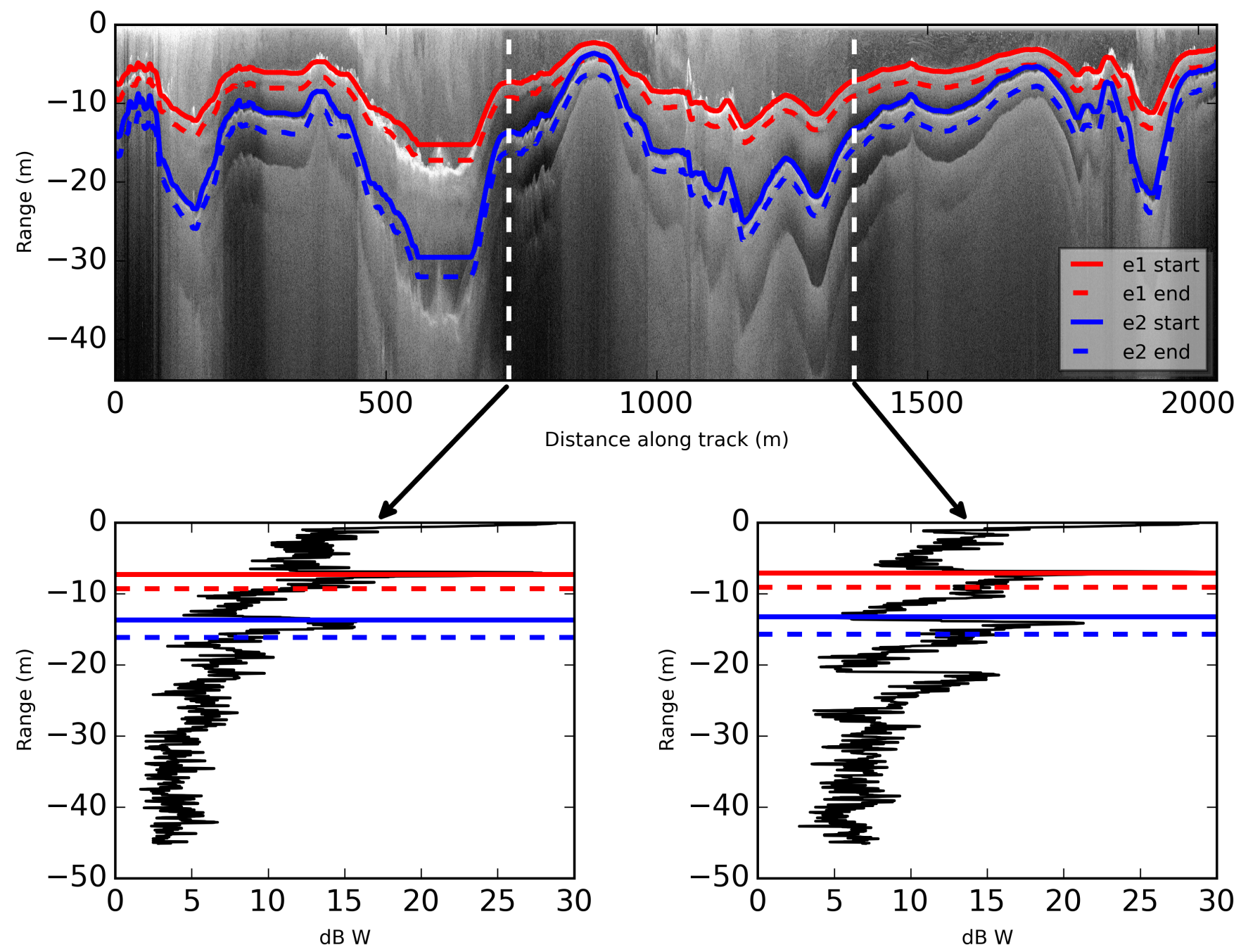

Figure 11: Echogram from the downward-looking echosounder recorded during the survey, with locations of the first and second echo envelopes. Two example pings (time-series of intensities at a particular location) are reproduced below. 
a) $e_{1}$

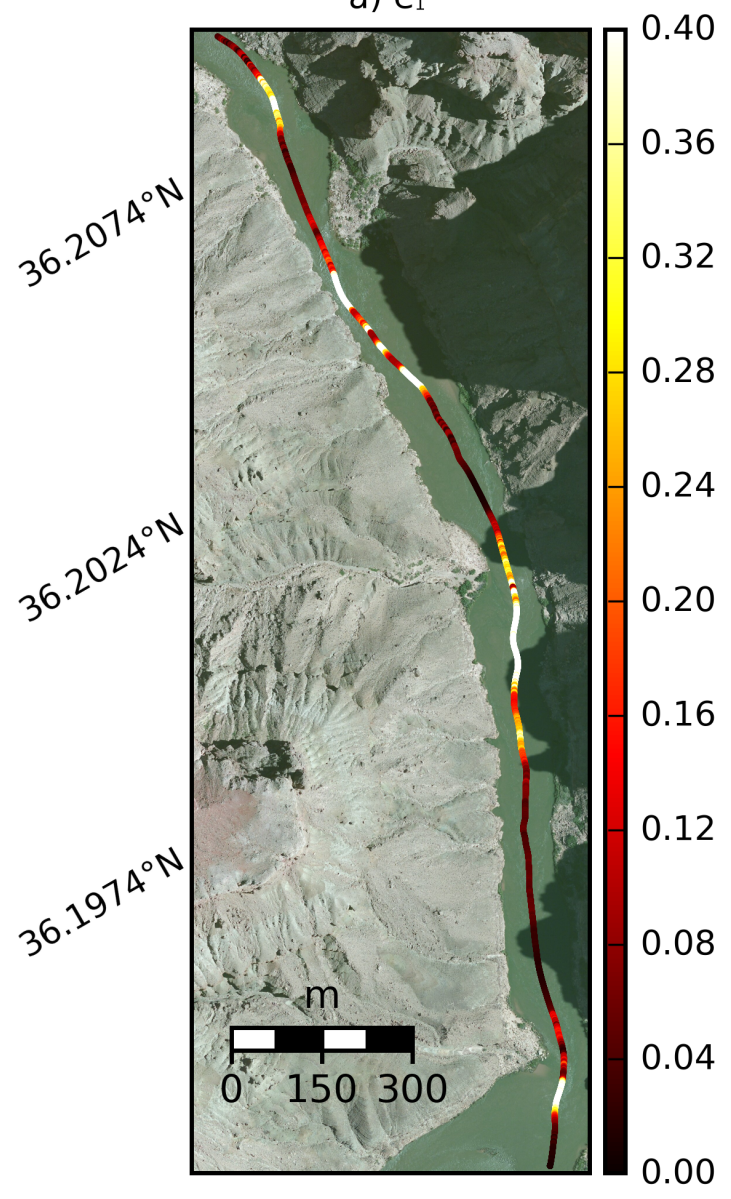

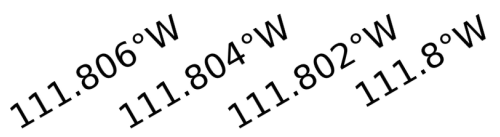

b) $e_{2}$

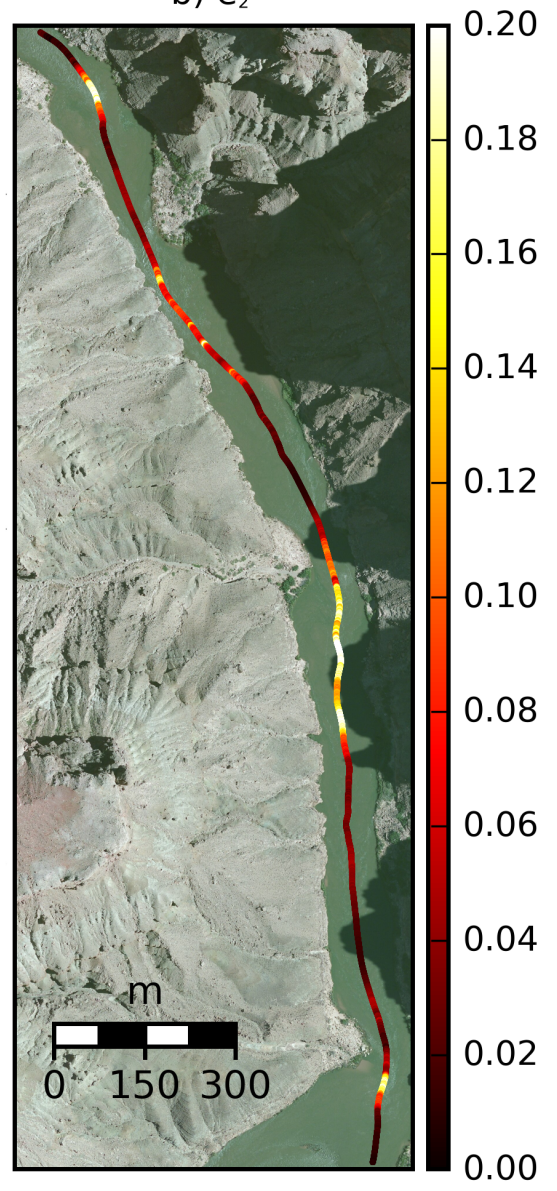

$11 . .800^{\circ \mathrm{W}} 11.80^{\circ \mathrm{W}} 11 . \mathrm{O}^{\circ \mathrm{W}}$ c) Acoustic class

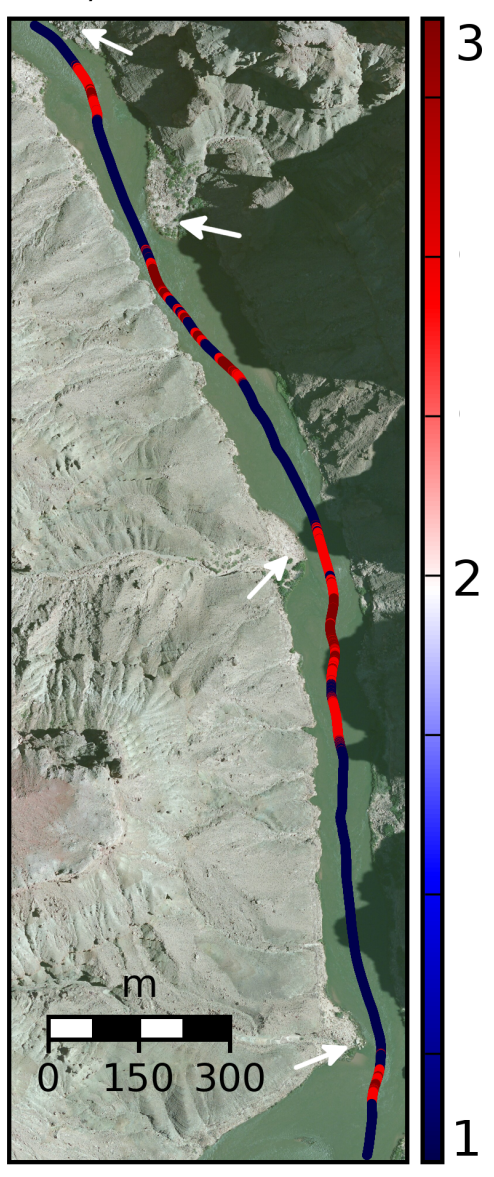

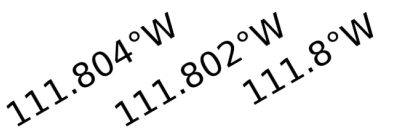

Figure 12: Bed characterization using a) $e_{1}$ coefficient; b) $e_{2}$ coefficient; c) acoustic classes based on a $k$-means clustering analysis. Debris fans have been highlighted with arrows. Below each fan, is a distinct acoustic class associated with coarser sediment. 
groupings (clusters) further reveals regions of rough/coarse sediment immediately adjacent to and downstream of debris fans (Figure 12).

\section{Computer program}

PyHum is a command-line program implemented in the popular (e.g. Karssenberg et al., 2010; Zhang et al., 2013; Horsburgh et al., 2015) Python (platform-independent, objectoriented) language, with computationally demanding procedural subroutines written in Cython using C-style static type declarations which allows compilation of static objects for efficiency. Numerical computations in PyHum are built around the efficiency of the NumPy array, utilizing Cython's support for fast access to NumPy arrays. Additional numerical libraries are provided by SciPy and Scikit-learn (Pedregosa et al., 2011). The design of PyHum is modular which allows code readability, easy extension and adaptations in the future, and the portability of its core functionality into other geospatial and geophysical analysis tools. The program includes numerous optimizations for speed and memory efficiency, using parallel processing, memory-mapped files and out-of-core processing where necessary.

Currently, PyHum consists of eight main sub-modules: read for reading data into the program and carrying out bed-picking and water-column removal (section 4); correct for radiometric corrections (section 5); rmshadows for manual or automated identification and removal of portions of echograms classified as acoustic shadow regions (section 6); texture for calculation of texture lengthscale maps, implementing the algorithm suggested by Buscombe et al. (2015) for physically based texture segmentation of sidescan echograms (section 8); map for georectification of the echogram (section 7); map texture for mapping results 
from the texture module; mosaic for mosaicking of several overlapping scans (each analyzed using the map module) into a composite sidescan map, whereby mosaicking is carried out by weighting the sidescan point clouds, with weights based on either grazing angle, proximity to the sonar, sidescan intensity, or user-defined combinations of these; and e1e2 for full waveform analysis of data from downward-looking echosounder echograms (section 9). Each module can be accessed modularly from within a Python script, or through a graphical user interface (GUI) by issuing the following from the command line: python -c "import PyHum; PyHum.gui()". Further installation and implementation details are described in Appendix A.

\section{Discussion and potential future directions}

The methods proposed in this contribution have been developed and tested using data from a number of different shallow aquatic environments, within the assumptions listed in section 2.2 , meeting a primary objective of providing fully-automated procedures to create reasonably accurately and precisely located, georectified and geometrically corrected scans of the bed that are standardized radiometrically, and without large acoustic shadows. Encoding these procedures in an open-source and freely available software package offers numerous advantages to the wider-community aside from the immediate practical benefits, including transparency, reproducibility, and a potential platform on which for others to adapt, and build on, the procedures. For example, in deeper, or more saline, and/or thermally stratified water bodies, the assumption of a constant sound propagation speed obviously breaks down and would have deleterious effects on the data without a ray-tracing algorithm to correct 
reported ranges (Blondel, 2009). In water bodies displaying large or abrupt variations in water depth, manual intervention during surveys in setting appropriate pulse lengths for the water depth is appropriate to maintain a quasi-constant across-track resolution. In deeper water, or flatter beds, the effects of anamorphism discussed in section 7.1 would be more noticeable (Cervenka and De Moustier, 1993). Simple modifications to the program could be made to incorporate these, and many other, potential changes which would be important in specific circumstances.

Ideal conditions for acoustic imaging using sidescan are usually when the sonar is moving at a constant slow speed in a straight line, such that the boat is not crabbing at an angle to the current, in which case the assumption that course-over-ground approximates heading is significantly violated. In addition, it is best if the sonar is located in the deepest available water, imaging a bed that is relatively flat, or failing that, the sonar-target geometry is such that the beams are ensonifying an area that is not sloping away from the plane of ensonfication. In quasi-trapezoidal channels, lake and coastal margins, positioning the boat mid-channel in the deepest water should usually meet this objective. Irregular channel shapes may require some pre-survey reconnaissance to evaluate the best course. Some guidance is provided in section 7.1 on ideal vessel speeds during surveying. Speed reported by recreational-grade GPS receivers are based on Kalman filtering, so are reasonably accurate even when reported positions are not (Hide et al., 2003). Sonar draft is usually best at least 20-30 $\mathrm{cm}$ below the water surface, to avoid cavitation and acoustic interference with the surface.

Swaths in very shallow water $(\leq 1 \mathrm{~m})$ are thin, and the echosounder often fails to ac- 
curately report depth. In this situation, the automated bed-picking algorithm detailed in section 4.2 becomes increasingly more useful. Similarly, when sediment concentrations are high, the acoustical estimate of the bed location (Equation 4) often fails, but the imageprocessing estimate can be remarkably robust. High concentrations of suspended sediment or bubbles would saturate the acoustic signal, but more work is needed to evaluate at what sediment concentrations and grain size, or what bubble density and size, the signal degradation is too severe to obtain usable data.

Future experimental work should address positional uncertainties, such as the propagation or errors from inaccurate transducer locations and instantaneous heading, and the effects of rectification over non locally flat beds without a known bathymetry. Here, the sidescan data are not 'calibrated', or quantitative, in the strict acoustical sense of the word, which would imply absolute magnitudes of intensity, but instead 'compensated', or relative magnitudes of acoustic intensity. However, the relative acoustic units ( $\mathrm{dB} W$ ) that the scans are converted into here should be qualitatively useful in a comparative sense between different environments with identical processing and similar sonar systems. Future work should concentrate on evaluating and calibrating the automated semi-empirical methods presented in sections 8 and 9, as well as other approaches, against independent observations of the bed substrates, for a variety of clastic and biogenic sediments, submerged aquatic vegetation types, and beds of sessile organisms. 


\section{Summary}

In recent years, inexpensive, vessel-mounted, so-called 'recreational grade' sonar systems have rapidly become popular among aquatic scientists, particularly in the field of benthic ecology, for swath imaging and mapping in shallow water. Unlike conventional sonar systems, 'recreational grade' systems have minimal logistical requirements and require no specialist knowledge to use. To support this 'democratization' of the technology among a growing interdisciplinary community of aquatic scientists with little to no experience in acoustical imaging of benthic environments, in this contribution methods have been proposed, based on simplified models for the sonar-target geometry and the nature of acoustic backscattering and attenuation in shallow water, to carry out geometric and radiometric correction and georectification of sonar echograms. These procedures also include a robust procedure for automated identification and removal of the acoustic shadows in shallow water, an algorithm for identification of bed-water interface, and automated bed substrate classification based on echo shape analysis. Collectively, these methods should further facilitate use of recreationalgrade sidescan sonar, in a fully automated and objective manner. These techniques are encoded in an open-source and freely-available software package, PyHum, for the analysis of data from the Humminbird ${ }^{\circledR}$ series of recreational-grade sonar. The processing steps have been demonstrated using a data set from a shallow freshwater environment (Colorado River in Grand Canyon, AZ) but should be equally applicable in all shallow fluvial, coastal, estuarine, and lacustrine environments. 


\section{Acknowledgements}

This work was funded by the Glen Canyon Dam Adaptive Management Program ad-

ministered by the U.S. Bureau of Reclamation. Any use of trade, product, or firm names is for descriptive purposes only and does not imply endorsement by the U.S. government. Barbara Faggetter provided some file format and sonar information, and the e1e2 module of PyHum is based on her code. Thanks to Ted Melis, Paul Grams, and Michael Yard for helping collect the field data and for helpful discussions. Thanks also to many PyHum users for identifying software bugs, and helpful software suggestions, especially Daniel Hamill, and also Cameron Bodine, Liam Zarri, and Rick Debbout for debugging and testing.

\section{Appendix A. Computer program implementation and installation}

- PyHum is completely open-source and has been developed under a GNU General Public License. The project homepage is http://dbuscombe-usgs.github.io/PyHum/ which provides documentation and further analysis examples.

- The program requires a number of additional python libraries for numerical computations (NumPy, SciPy, Cython, joblib, pandas, dask, toolz, scikit-learn, scikit-image), cartography and gridding (pyresample, pykdtree, pyproj), and graphics (simplekml, matplotlib, and matplotlib-basemap). A setup.py distutils script is provided to automatically install these dependencies.

- The program is available on the Python package repository (https://pypi.python. org/pypi/PyHum) and can be installed from the command line using: pip install 
PyHum.

- PyHum has a git version-control backend and is freely available on the github ${ }^{\circledR}$ online repository: https://github.com/dbuscombe-usgs/PyHum which allows centralized storage and customization by users through development branches. Additions of new functions and sub-modules can be made or incorporated into other software tools by interested developers.

- sphinx has been used to generate html web pages for the project. These can be compiled locally using the supplied Makefile (make html) or batch (make.bat) file on a Windows ${ }^{\circledR}$ operating system. Documentation and API, including several example usages of the program, can be found at the program's website (http://dbuscombe-usgs . github.io/PyHum/).

\section{References}

Allen, Y.C., Wilson, C.A., Roberts, H.H., Supan, J., 2005. High resolution mapping and classification of oyster habitats in nearshore Louisiana using sidescan sonar. Estuaries 28, 435-446.

Amiri-Simkooei, A., Snellen, M., Simons, D.G., 2009. Riverbed sediment classification using multi-beam echo-sounder backscatter data. Journal of the Acoustical Society of America 126, 1724-1738.

Amiri-Simkooei, A.R., Snellen, M., Simons, D.G., 2011. Principal component analysis of single-beam echosounder signal features for seafloor classification. IEEE Journal of Oceanic Engineering 36, 259-272.

Anima, R.J., Wong, F.L., Hogg, D., Galanis, P., 2007. Side-scan sonar imaging of the Colorado River, Grand Canyon. US Geological Survey Open-File Report 2007-1216.

Atallah, L., Smith, P.P., Bates, C., 2002. Wavelet analysis of bathymetric sidescan sonar data for the classification of seafloor sediments in hopvågen bay-norway. Marine Geophysical Researches 23, 431-442. 
Betts, D., Derrow, R., Howells, D., 2010. Side scan sonar imaging system with enhancement. URL: https://www.google.com/patents/US7755974.

Bilkovic, D.M., Havens, K., Stanhope, D., Angstadt, K., 2014. Derelict fishing gear in Chesapeake Bay, Virginia: Spatial patterns and implications for marine fauna. Marine Pollution Bulletin 80, 114-123.

Blondel, P., 2009. The handbook of sidescan sonar. Springer Science and Business Media, Berlin.

Brown, C.J., Smith, S.J., Lawton, P., Anderson, J.T., 2011. Benthic habitat mapping: A review of progress towards improved understanding of the spatial ecology of the seafloor using acoustic techniques. Estuarine, Coastal and Shelf Science 92, 502-520.

Burguera, A., Oliver, G., 2016. High-resolution underwater mapping using side-scan sonar. PloS one 11, e0146396.

Burns, D., Queen, C., Sisk, H., Mullarkey, W., Chivers, R., 1989. Rapid and convenient acoustic seabed discrimination. Proceedings of the Institute of Acoustics 11, 169-178.

Buscombe, D., 2016. Spatially explicit spectral analysis of point clouds and geospatial data. Computers \& Geosciences 86, 92-108.

Buscombe, D., Grams, P.E., Kaplinski, M.A., 2014a. Characterizing riverbed sediments using high-frequency acoustics 1: Spectral properties of scattering. Journal of Geophysical Research - Earth Surface 119, doi:10.1002/2014JF003189.

Buscombe, D., Grams, P.E., Kaplinski, M.A., 2014b. Characterizing riverbed sediments using high-frequency acoustics 2: Scattering signatures of Colorado River bed sediments in Marble and Grand Canyons. Journal of Geophysical Research - Earth Surface 119, doi:10.1002/2014JF003191.

Buscombe, D., Grams, P.E., Smith, S.M., 2015. Automated riverbed sediment classification using low-cost sidescan sonar. Journal of Hydraulic Engineering , 06015019, doi:10.1061/(ASCE)HY.1943-7900.0001079.

Cervenka, P., De Moustier, C., 1993. Sidescan sonar image processing techniques. IEEE Journal of Oceanic Engineering 18, 108-122.

Cervenka, P., De Moustier, C., Lonsdale, P.F., 1994. Geometric corrections on sidescan sonar images based on bathymetry. Application with SeaMARC II and Sea Beam data. Marine Geophysical Researches 16 , 
365-383.

Cheek, B.D., Grabowski, T.B., Bean, P.T., Groeschel, J.R., Magnelia, S.J., 2016. Evaluating habitat associations of a fish assemblage at multiple spatial scales in a minimally disturbed stream using low-cost remote sensing. Aquatic Conservation: Marine and Freshwater Ecosystems 26, 20-34. doi:10.1002/aqc . 2569.

Chesterman, W., Clynick, P., Stride, A., 1958. An acoustic aid to sea bed survey. Acustica 8, 285-290.

Cobra, D.T., Oppenheim, A.V., Jaffe, J.S., 1992. Geometric distortions in side-scan sonar images: a procedure for their estimation and correction. IEEE Journal of Oceanic Engineering 17, 252-268.

Collier, J., Brown, C., 2005. Correlation of sidescan backscatter with grain size distribution of surficial seabed sediments. Marine Geology 214, 431-449.

Collins, K., Suonpää, A., Mallinson, J., 2010. The impacts of anchoring and mooring in seagrass, Studland Bay, Dorset, UK. Underwater Technology 29, 117-123.

Costello, M.J., 2009. Distinguishing marine habitat classification concepts for ecological data management. Marine Ecology Progress Series 397, 253-268.

Diaz, R.J., Solan, M., Valente, R.M., 2004. A review of approaches for classifying benthic habitats and evaluating habitat quality. Journal of Environmental Management 73, 165-181.

Dunlop, R.A., Noad, M.J., McCauley, R.D., Kniest, E., Slade, R., Paton, D., Cato, D.H., 2016. Response of humpback whales (Megaptera novaeangliae) to ramp-up of a small experimental air gun array. Marine Pollution Bulletin 103, 72-83.

Ehrhold, A., Hamon, D., Guillaumont, B., 2006. The REBENT monitoring network, a spatially integrated, acoustic approach to surveying nearshore macrobenthic habitats: application to the Bay of Concarneau (South Brittany, France). ICES Journal of Marine Science 63, 1604-1615.

Evenden, G.I., 1990. Cartographic projection procedures for the UNIX environment: A user's manual. United States Geological Survey Open-File Report 90-28.

Flowers, H.J., Hightower, J.E., 2013. A novel approach to surveying sturgeon using side-scan sonar and occupancy modeling. Marine and Coastal Fisheries 5, 211-223. doi:10.1080/19425120.2013.816396. 
Frieden, J.C., Peterson, E.E., Webb, J.A., Negus, P.M., 2014. Improving the predictive power of spatial statistical models of stream macroinvertebrates using weighted autocovariance functions. Environmental Modelling \& Software 60, 320-330.

Froehlich, C.Y., Kline, R.J., 2015. Using fish population metrics to compare the effects of artificial reef density. PloS One 10, e0139444. doi:doi:10.1371/journal.pone.0139444.

Geiger, D., Gupta, A., Costa, L.A., 1995. Dynamic programming for detecting, tracking, and matching deformable contours. IEEE Transactions on Pattern Analysis and Machine Intelligence 17, 294-302.

Goclowski, M.R., Kaeser, A.J., Sammons, S.M., 2013. Movement and habitat differentiation among adult shoal bass, largemouth bass, and spotted bass in the Upper Flint River, Georgia. North American Journal of Fisheries Management 33, 56-70.

Goff, J., Olson, H., Duncan, C., 2000. Correlation of side-scan backscatter intensity with grain-size distribution of shelf sediments, New Jersey margin. Geo-Marine Letters 20, 43-49.

Gonzalez-Socoloske, D., Olivera-Gomez, L.D., Ford, R.E., 2009. Detection of free-ranging West Indian manatees Trichechus manatus using side-scan sonar. Endangered Species Research 8, 249-257.

Hamill, D., Wheaton, J.M., Buscombe, D., Grams, P.E., Melis, T.S., 2016. Bed texture mapping in large rivers using recreational-grade sidescan sonar, in: Proceedings of the Eighth International Conference on Fluvial Hydraulics (RiverFlow 2016), pp. 306-312.

Hamilton, L., 2014. Real-time echosounder based acoustic seabed segmentation with two first echo parameters. Methods in Oceanography 11, 13-28.

Hamilton, L., Mulhearn, P., Poeckert, R., 1999. Comparison of RoxAnn and QTC-View acoustic bottom classification system performance for the Cairns area, Great Barrier Reef, Australia. Continental Shelf Research 19, 1577-1597.

Haralick, R.M., 1979. Statistical and structural approaches to texture. Proceedings of the IEEE 67, 786-804.

Havens, K., Bilkovic, D.M., Stanhope, D., Angstadt, K., 2011. Fishery failure, unemployed commercial fishers, and lost blue crab pots: an unexpected success story. Environmental Science and Policy 14, 445-450. 
Hide, C., Moore, T., Smith, M., 2003. Adaptive Kalman filtering for low-cost INS/GPS. The Journal of Navigation 56, 143-152.

Hobbs, C.H., 1985. Side-scan sonar as a tool for mapping spatial variations in sediment type. Geo-Marine Letters 5, 241-245.

Horsburgh, J.S., Reeder, S.L., Jones, A.S., Meline, J., 2015. Open source software for visualization and quality control of continuous hydrologic and water quality sensor data. Environmental Modelling \& Software 70, 32-44.

Jackson, D.R., Richardson, M.D., 2007. High-frequency seafloor acoustics. Springer, New York.

Kaeser, A.J., Litts, T.L., 2008. An assessment of deadhead logs and large woody debris using side scan sonar and field surveys in streams of southwest Georgia. Fisheries 33, 589-597.

Kaeser, A.J., Litts, T.L., 2010. A novel technique for mapping habitat in navigable streams using low-cost side scan sonar. Fisheries 35, 163-174.

Kaeser, A.J., Litts, T.L., Tracy, T., 2013. Using low-cost side-scan sonar for benthic mapping throughout the Lower Flint River, Georgia, USA. River Research and Applications 29, 634-644.

Karssenberg, D., Schmitz, O., Salamon, P., de Jong, K., Bierkens, M.F., 2010. A software framework for construction of process-based stochastic spatio-temporal models and data assimilation. Environmental Modelling \& Software 25, 489-502.

Kennish, M.J., Haag, S.M., Sakowicz, G.P., Tidd, R.A., 2004. Side-scan sonar imaging of subtidal benthic habitats in the Mullica River - Great Bay estuarine system. Journal of Coastal Research , 227-240.

Kenny, A., Cato, I., Desprez, M., Fader, G., Schüttenhelm, R., Side, J., 2003. An overview of seabedmapping technologies in the context of marine habitat classification. ICES Journal of Marine Science 60, $411-418$.

Kitchingman, A., Tonkin, Z., Lyon, J., 2013. A novel approach to spatially assessing instream woody habitat densities across large areas. Journal of Environmental Management 128, 555-560.

Kleeman, L., Kuc, R., 2008. Sonar sensing, in: Springer Handbook of Robotics. Springer, pp. 491-519.

Klein, M., Edgerton, H., 1968. Sonar: a modern technique for ocean exploitation. IEEE Spectrum 5, 40-46. 
Kovesi, P., 2012. Phase preserving tone mapping of non-photographic high dynamic range images, in: IEEE Digital Image Computing Techniques and Applications (DICTA 2012), pp. 1-8.

La Croix, A.D., Dashtgard, S.E., 2015. A synthesis of depositional trends in intertidal and upper subtidal sediments across the tidal-fluvial transition in the Fraser River, Canada. Journal of Sedimentary Research 85, 683-698.

Lamarche, G., Lurton, X., Verdier, A.L., Augustin, J.M., 2011. Quantitative characterisation of seafloor substrate and bedforms using advanced processing of multibeam backscatter Application to Cook Strait, New Zealand. Continental Shelf Research 31, S93-S109.

Lurton, X., 2003. Theoretical modelling of acoustical measurement accuracy for swath bathymetric sonars. The International Hydrographic Review 4, 17-30.

Marsili-Libelli, S., Giusti, E., Nocita, A., 2013. A new instream flow assessment method based on fuzzy habitat suitability and large scale river modelling. Environmental Modelling \& Software 41, 27-38.

Mitchell, N.C., Somers, M., 1989. Quantitative backscatter measurements with a long-range side-scan sonar. IEEE Journal of Oceanic Engineering 14, 368-374.

Muñoz-Mas, R., Martínez-Capel, F., Garófano-Gómez, V., Mouton, A.M., 2014. Application of probabilistic neural networks to microhabitat suitability modelling for adult brown trout (Salmo trutta L.) in Iberian rivers. Environmental Modelling \& Software 59, 30-43.

Pedregosa, F., Varoquaux, G., Gramfort, A., Michel, V., Thirion, B., Grisel, O., Blondel, M., Prettenhofer, P., Weiss, R., Dubourg, V., Vanderplas, J., Passos, A., Cournapeau, D., Brucher, M., Perrot, M., Duchesnay, E., 2011. Scikit-learn: Machine learning in Python. Journal of Machine Learning Research 12, $2825-2830$.

Powers, J., Brewer, S.K., Long, J.M., Campbell, T., 2014. Evaluating the use of side-scan sonar for detecting freshwater mussel beds in turbid river environments. Hydrobiologia 743, 127-137.

Reed, T.B., Hussong, D., 1989. Digital image processing techniques for enhancement and classification of SeaMARC II side scan sonar imagery. Journal of Geophysical Research 94, 7469-7490.

Roberts, J.J., Best, B.D., Dunn, D.C., Treml, E.A., Halpin, P.N., 2010. Marine geospatial ecology tools: 
An integrated framework for ecological geoprocessing with ArcGIS, Python, R, MATLAB, and C++. Environmental Modelling \& Software 25, 1197-1207.

Ryan, D.A., Brooke, B.P., Collins, L.B., Kendrick, G.A., Baxter, K.J., Bickers, A.N., Siwabessy, P.J., Pattiaratchi, C.B., 2007. The influence of geomorphology and sedimentary processes on shallow-water benthic habitat distribution: Esperance Bay, Western Australia. Estuarine, Coastal and Shelf Science $72,379-386$.

Serpetti, N., Heath, M., Armstrong, E., Witte, U., 2011. Blending single beam RoxAnn and multi-beam swathe QTC hydro-acoustic discrimination techniques for the Stonehaven area, Scotland, UK. Journal of Sea Research 65, 442-455.

Singh, H., Adams, J., Mindell, D., Foley, B., 2000. Imaging underwater for archaeology. Journal of Field Archaeology 27, 319-328.

Smit, R., Kaeser, A., 2016. Defining freshwater mussel mesohabitat associations in an alluvial, coastal plain river. Freshwater Science 35, 000-000.

Soille, P., 2013. Morphological image analysis: principles and applications. Springer Science and Business Media, Berlin.

Sonka, M., Hlavac, V., Boyle, R., 1993. Image Processing, Analysis, and Machine Vision, 2nd Edition. Chapman and Hall, London.

Sterrett, S.C., Kaeser, A.J., Katz, R.A., Smith, L.L., Brock, J.C., Maerz, J.C., 2015. Spatial ecology of female Barbour's Map turtles (Graptemys barbouri) in Ichawaynochaway Creek, Georgia. Copeia 103, $263-271$.

Surridge, B.W., Bizzi, S., Castelletti, A., 2014. A framework for coupling explanation and prediction in hydroecological modelling. Environmental Modelling \& Software 61, 274-286.

Todd, B.J., Kostylev, V.E., 2011. Surficial geology and benthic habitat of the German Bank seabed, Scotian Shelf, Canada. Continental Shelf Research 31, S54-S68.

Urick, R.J., 1948. The absorption of sound in suspension of irregular particles. Journal of the Acoustical Society of America 20, 283-289. 
Urick, R.J., 1967. Principles of underwater sound for engineers. Tata McGraw-Hill Education, Noida, India.

Yeung, C., McConnaughey, R.A., 2008. Using acoustic backscatter from a sidescan sonar to explain fish and invertebrate distributions: a case study in Bristol Bay, Alaska. ICES Journal of Marine Science 65, $242-254$.

Zhang, X., Beeson, P., Link, R., Manowitz, D., Izaurralde, R.C., Sadeghi, A., Thomson, A.M., Sahajpal, R., Srinivasan, R., Arnold, J.G., 2013. Efficient multi-objective calibration of a computationally intensive hydrologic model with parallel computing software in Python. Environmental Modelling \& Software 46, 208-218. 